\title{
INVESTIGATING INDUSTRY DYNAMICS IN A RECESSIONARY TRANSITION ECONOMY
}

Vanja Vitezić, Stjepan Srhoj, Marko Perić

\section{Abstract}

The paper investigates the statistical regularities of industry dynamics in a transition economy and its manufacturing industry over a six-year period of recession. The static analysis of distributions supports several established stylized facts on firm size and growth-rate distributions. The growth rate distribution featured a sequential, year-by-year procyclical change of the left side of distribution, suggesting that the more years an economy spends in a recession, the greater the decline in the revenue of its firms. On the "growing" side, the recession opened increasing growth opportunities for a small subset of small firms, while it diminished growth opportunities for medium and large firms. The segregation of sectors by technological intensity gives evidence that the high-tech sectors show upward trend of the growth rate distributions' right side of as the recession unfolded. Sectorial concentration ratios mostly increased, while changes in the unimodality of the firm-size distribution occurred at the end of the economic downturn.

Keywords: growth rate distribution; firm size distribution; technological intensity; recession; asymmetric exponential power

JEL Classification: $L 11, L 16, D 22$

\section{INTRODUCTION}

In the past twenty-five years, the countries of Central and Eastern European engaged in a number of policy experiments in the areas of planned growth and transformation into competitive markets, which has resulted in different national economic structures and growth patterns (Stojčić and Aralica, 2018). For transition countries, established institutions matter profoundly, as these "rules of the game" influence the economic outcomes at both the micro and macro level (Efendic \& Pugh, 2007). In the given institutional setting during the period 2006-2011, the global economic crisis, through a series of mechanisms, namely a lack of credit availability and trade financing, and decreases in consumption and investment, had a
Vanja Vitezić, PhD, Postdoc

Faculty of Tourism and Hospitality Management, University of Rijeka, Croatia E-mail:vanjav@fthm.hr.

Stjepan Srhoj, Teaching and research assistant, corresponding author

Department of Economics and Business Economics, University of Dubrovnik, Croatia.

E-mail: ssrhoj@unidu.hr.

Marko Perić, PhD, Associate professor Faculty of Tourism and Hospitality Management, University of Rijeka, Croatia

E-mail: markop@fthm.hr. 
major impact on economic growth (Pop et al., 2013). Compared to the EU average, the higher growth of most of the new cohesion countries in the period 2009-2011 was shown not to be sufficient to provide an adequate pace for convergence in the future (Farkas, 2013). According to Čaršimamović, Vukotić et al. (2013) for the Western Balkan countries the aftermath of the crisis compared to the pre-crisis period resulted in a strong decrease in real GDP growth rate potential, which roughly halved on average. This could have been the result of uncompleted regulation reforms, and «bank-based» financial systems that were predominantly foreign-owned (Farkas, 2017). The lingering Croatian recession (similar to Greece) revealed the structural infirmity of the economy, with suma summarum an estimated cumulative GDP decrease of $12 \%$ (lootty et al., 2014). Given the importance of manufacturing for economic growth in developing countries, the aim of this paper is to analyze industry dynamics during the economic crisis (2009-2013) in the Republic of Croatia.

In the literature on industry dynamics, investigating firm growth rate and size distributions have attracted research attention over the last fifteen years. The focus on manufacturing sectors is common in firm size and firm growth distribution studies (e.g. Heinrich and Dai, 2016; Dusch and Peng, 2015), as they are assumed to have a leading role in the process of rebuilding after a recessionary period (Pisano and Shih, 2009). Investigating empirical distributions has theoretical implications, as these findings place constraints on theoretical models (Williams et al., 2015; Bottazi and Secchi, 2006). So far, a robust statistical structure has been found across countries, which in turn has prompted scholars to propose theoretical models explaining these distributions with real economic forces as opposed to mere measurement coincidence. The majority of studies on firm growth rates distribution were conducted in periods of economic prosperity, but only a small number in periods of economic recession (Perić and Vitezić, 2016). The literature initially started to question the aggregate shapes of growth rate and firm size distributions in the manufacturing sectors (Dosi et al., 1995), as these might be simply due to "sheer aggregation among firms belonging to different sectors characterized by different regimes of market interaction and of organizational and technological learning" (Dosi et al., 2010, p.1869). The primary question of most papers was whether firm size and firm growth rate distribution can survive disaggregation. Recently, Bottazzi et al. (2014) and Duschl and Peng (2015) highlighted the differences in manufacturing firms' growth rate distributions depending on their context; thus, for example, a recession period in a transition economy and/or firm characteristics such as firm size and technological intensity.

Given the OECD's (1994, 2003) ${ }^{1}$ and Hatzichronoglou's (1997) division of manufacturing sectors into high-, medium-high, medium-low and low-tech based on their "innovation input", that is, R\&D spending, we were interested in analyzing the behavior of the firm size and growth distributions of these sectors during a recession. Declining production during a recession in high-tech manufacturing sectors was only half as large as in the total industry (Jaegers et al., 2013). Along these lines, low-tech manufacturing firms seem to be more affected by the crisis than their high-tech counterparts (Caloghirou et al., 2014). It is presumed that lower costs of labor have a repercussion on the growth of labor-intensive and price competitive manufacturing sectors, while at the same time this does not hold for highly skilled personnel in knowledge and technology-driven sectors (Stojčić and Aralica, 2018).

We seek to contribute to the literature by investigating growth rate distribution evolution and the firm size distribution of manufacturing firms in a transition economy during a unique six-year recession period. This paper provides a model that describes the characteristics of firm distributions in the case of a prolonged recession. For the latter we start by investigating whether firm size distribution at the aggregate level survives analysis on a finer level (NACE 3-digit). Firm size distribution was first analyzed using kernel density estimates at the aggregate (manufacturing) level, then at two categories derived from the OECD classification, high-tech (high- and medium-high firms) and low-tech (medium-low and low-tech firms). At the NACE 3-digit level, the bimodality test was applied to check the modes of firm size distribution at the sector level. In addition, the upper tail of firm size distribution was analyzed with the concentration ratio. For the growth rate distribution, we again used kernel density estimates, which were followed by an analysis of flexible asymmetric exponential power (AEP) density for each year the economy spent in recession. These analyses were conducted at the aggregate manufacturing level, micro/small firm level, medium/large firm level as well as the high- and low-tech sector levels. Finally, we report the change in firm growth rates at the beginning and at the end of the period analyzed for the

\footnotetext{
1 The technology-intensity classification is relative due to the fact that many manufacturing activities could be considered "high -tech", but by looking at direct R\&D intensities they are classified according to relatively recent R\&D performance. Also, "high-tech" industries can produce a variety of products, ranging from "lowtech" and "high-tech". The idea was to create a classification for the OECD as a whole.
} 
NACE 2-digit sectors.

The rest of the paper is structured as follows. The first three chapters review the literature on firm size distribution, firm growth rate and technological intensity. The fifth chapter explains the data used and the sixth the study's methods. The seventh chapter gives its results, while the eighth chapter discusses the results and offers conclusions.

\section{FIRM SIZE DISTRIBUTION}

Firm size distributions still seem to be not well-understood (Heinrich and Dai, 2016) although they have been researched from many angles. Cabral and Mata (2003) find that the distribution of the logarithm of firm size is skewed to the right but evolves over time towards log normal, while Bottazzi et al. (2015) argue that the firm size distribution tail can be well explained by Zipf's Law. However, there is no generally accepted theory of how the distribution of firm sizes emerges. An overview of potential candidates was given by Heinrich and Dai (2016) who note that firm size distribution in China follows the power law, which is slightly higher than those reported for other countries, and that firm size distributions hold for regional firm size distributions. Fat-tailed firm size distribution has been found to hold across countries and time (Zhang et al., 2009). Other studies (e.g. Bottazzi et al., 2011, Bottazzi et al., 2007, Bottazzi and Secchi, 2003), however, find this distribution to only hold on an aggregate level, but not on a disaggregated level. Because aggregate firm size distribution does not survive disaggregation, firm size distribution did not become as fruitful a research field as growth rate distribution.

The aforementioned researchers checked firm size distribution "survival" at the sectorial level using the bimodality (multimodality) test. This test assesses the modality or the "bumps" in distributions (Xu et al., 2014); in essence, it looks at whether the firm size distributions at the sector level have a single peak, indicating one common firm size range. Bottazzi and Secchi (2003) found considerable heterogeneity in the distribution of firm size across sectors and a high probability of the presence of bimodality. Bottazzi et al. (2007) argue that aggregate firm size densities are characterized by a right-skewed bell-shape. Unimodality was rejected in most sectors using different size measures (total sales, number of employees, and value added), although different firm size definitions led to different sectors being rejected as unimodal (Bottazzi et al., 2007). Bottazzi et al. (2011) further reject unimodality in 18 out of 20 sectors, which offers, together with the previously mentioned papers, robust evidence that the characteristic aggregate shape of firm size distribution observed is mainly an outcome of aggregation.

There are several theoretical models explaining the shape of firm size distribution with financial constraints (Cabral and Mata, 2003), innovation and research attempts (Heinrich and Dai, 2016) or the user base of the products (Heinrich, 2013; 2014), among other things. However, there seems to be no economic theory on how firm size distributions behave as a recession unfolds. The empirical evidence suggests that during recession periods firms face a drop in revenue (Knudsen and Lien, 2014) and they seem to be more financially constrained (Bakke, 2009; Gilchrist and Sim, 2007), while investors' confidence and expectations are lower (Zenghelis, 2012). While these arguments might lead in the direction of changes in average firm size as a recession unfolds, the modality should not change to a large extent. This should be the case, as many papers (e.g. Holly et al., 2012; Bottazzi et al., 2011; Bottazzi et al., 2007; Higson et al., 2004; Higson et al., 2002; Bottazzi and Secchi, 2003; Hardwick and Adams, 2002; Contini and Revelli, 1989) find most firms' growth rates to be around zero even during recessions, while a change of modality (e.g. from one mode into two) would imply the high growth/decline rates of many firms and/or the substantial decrease of firms with growth rates close to zero.

Another interesting feature is sectorial concentration, which can be explained as the analysis of the distributions' upper tail. The literature is abundant in industrial concentration analysis (e.g. Bai et al., 2014; Chiang et al., 2001; Cabral, 2000; Bain, 1968) because it deals with market power. Firms with higher market power can increase prices and lower quantities, leading to overall socially inefficient outcomes (Tirole, 1988), which, in an industrial organization, is often analyzed within the structure-conduct-performance (S-C-P) paradigm (see Bain, 1968; Tirole, 1988; Cabral, 2000). Empirically, Bottazzi et al. (2007) found that the sectorial concentration ratio was persistent and had not changed significantly in Italy during the 1989-1997 period of their dataset. Bottazzi et al. (2011) reported great variations, ranging from 0.33 to 0.72 , within average sector concentration in French manufacturing industries during the period 1996-2002. However, it is not straightforward as to how changes in concentration ratios of different sectors should behave as a recession unfolds. This ambiguity stems from different levels of dependency on external finances in sectors (Braun and Larrain, 2005), possible changes in regulation (Tipurić and Pejić Bach, 2009), industry life-cycle (Shapiro, 2009) and numerous firm-specific characteristics (see Bharadwaj and Varadarajan, 2005). Coricelli 
et al. (2012) reported a slight increase in industrial concentration as the recession unfolded. The reasons for these increases in concentration ratio might partly be found in the S-C-P paradigm, which states that a higher concentration leads to higher average profit rates (Cabral, 2000). While this paradigm ignores numerous firm-specific characteristics (Bharadwaj and Varadarajan, 2005), it provides a broad guideline. Namely, in general, firms with higher market power should reap higher profits, which in a recession leads to the relatively higher availability of resources, making these firms more liquid and allowing them higher financing opportunities, both critical components during recessions (Geroski and Gregg, 1997). In turn, these firms with resources can more easily further increase their market share.

Based on our review of firm size distribution, we presume that the distributions in our sample will not survive disaggregation accompanied by a substantial variation in concentration ratio.

\section{GROWTH RATE DISTRIBUTION}

The research stream on firm growth rate distributions began as a natural extension of the massive research undertaken on Gibrat's (1931) Law of Proportionate Effect (e.g. Mansfield, 1962; Sutton, 1997; Audretsch et al., 1999; Calvo 2006; Lotti et al., 2009; Coad, 2007; Fotopoulos and Giotopoulos, 2010; Perić and Vitezić, 2016). Scholars from industrial organizations have focused substantial efforts on studying growth rate distribution as it deals with the statistical regularities of industry dynamics (e.g. Bottazzi et al., 2002; Bottazzi and Secchi, 2003; Reichstein and Jensen, 2005; Bottazzi et al, 2011; Lunardi et al, 2014; Duschl and Peng, 2015; Yu et al. 2015). These empirical findings then place constraints on the theoretical models, explaining firm growth in a general or in a specific context. The literature initially began to investigate whether growth rate distribution represents a normal distribution ${ }^{2}$, which was clearly rejected on multiple occasions (e.g. Bottazzi and Secchi, 2003; Reichstein and Jensen, 2005; Bottazzi et al, 2011), and whether aggregate growth rate distribution can survive disaggregation, which was confirmed (e.g. Bottazzi and Secchi, 2003; Bottazzi et al, 2011). It became something like a stylized fact in industrial organizations that growth rate distributions are fatter than a Gaussian distribution, mostly resembling a Laplace distribution (Dosi et al., 2010; Williams et al.,

2 A feature of Gibrat's (1931) Law is that under the central limit theorem growth rates should be well described by a Gaussian (normal) distribution.
2015), Exponential Power Distribution (Bottazzi et al., 2014; Duschl and Peng, 2015) or even Cauchy distribution (Williams et al., 2015).

Stanley et al. (1996), Bottazzi et al. (2001) and Bottazzi and Secchi (2003) find that a tent-shaped growth rate distribution best describes the manufacturing industry and pharmaceutical industry around the globe. Giulio Bottazzi methodologically advanced the research on growth rates distribution by introducing a parametric approach to check whether the Subbotin family of distributions (Subbotin, 1923) can confirm fat (heavy) tailed distribution. The results first pointed to a symmetrical Laplace distribution in the Italian manufacturing sector (Bottazzi and Secchi, 2003), but later research found somewhat asymmetrical distributions in Danish and French manufacturing sectors (Reichstein and Jensen, 2005; Bottazzi et al. 2011), with right tails being fatter than the left ones. This finding can be interpreted as a higher frequency of high-growth events in comparison with high-decline events in these industries. Bottazzi et al. (2011) report heterogeneity between sectors and across studies (e.g. when compared with previous work in the United States and Italy; Stanley et al., 1996 and Bottazzi et al., 2002), which is why they consider more research on the topic needed. Lunardi et al. (2014) found the Laplace distribution to be a useful approximation for most of the manufacturing subsectors studied. However, at the sector level, there was no typical shape. Therefore, based on the review of empirical evidence we join in arguing that the growth rate distribution of firms, sectors and industries is still an open and provocative topic, with the assumption that the growth rate distributions in our sample will be heavy tailed and will survive disaggregation.

Recently, several papers (e.g. Bottazzi et al., 2014; Duschl and Peng, 2015) have suggested the usage of a more flexible asymmetric exponential power (AEP) density, which takes into account the left and right shape and scale parameters (for details see Bottazzi and Secchi, 2011). In the context of this paper, the literature (e.g. Reichstein and Jensen, 2005; Bottazzi et al., 2014; Duschl and Peng, 2015) provides two interesting findings. First, context matters for the shape of growth rate distributions. The most obvious difference is between distributions reported for Chinese firms (Duschl and Peng, 2015) and those of French (Bottazzi et al., 2011) or Italian (Bottazzi et al., 2007) firms. However, even within Europe there seem to be some differences. A notable difference can be seen between empirical findings from Denmark (Reichstein and Jensen, 2005), where the left tail tended towards a Gaussian distribution, and empirical findings from Italy, where the growth rates were Laplacian or thicker 
(Bottazzi et al., 2014). Second, the basic characteristics of firms matter for growth rate distributions (Bottazzi et al., 2014; Duschl and Peng, 2015). For these reasons, we turn our analysis not only towards a specific context, a six-year recession, but also towards high-tech and low-tech sectors (chapter 4) as proposed by the OECD (2003).

The recession-productivity growth link is described by the idea of creative destruction (Caballero and Hammour, 1994). However, in addition to the effect of creative destruction, another interesting question arises in changes among those firms that were active prior to, but also survived, the recession (the longliving more-efficient supply base). Empirically, Ogawa and Tanaka (2013) identified three shocks related to recession, the demand, supply, and financial shocks. It is well known that the great recession of 2008-2009 hit the entrepreneurial sector worldwide, resulting in adverse effects on production and product lines (Liu, 2009), investments (Campello et al., 2010; Buca and Vermeulen, 2012), performance (Akbar et al., 2013), sales (Cowling et al., 2015), employment (Rafferty et al., 2013), risk tolerance (Inklaar and Yang, 2012), and business confidence (Geels, 2013). Nevertheless, during the economic downturn firms could also invest in their innovation capability to strengthen their competitiveness for the period of economy recovery (Flammer and loannou, 2015), which is in line with the pit-stop view of recessions (Aghion and SaintPaul, 1998). In addition, Geroski (1993) claimed that innovating firms were much less sensitive to cyclical shocks than non-innovating firms. Vice versa, sometimes firms react by cutting back investment in innovation. This is a move more likely to be seen in larger-size firms with higher innovation intensity ${ }^{3}$. It is not completely clear, however, as to how many firms stop their on-going projects and to which magnitude they put a stop on new innovation projects (Filippetti and Archibugi, 2011), which is why it is not completely clear how firm size and growth rate distributions change as a recession unfolds. Evidence from Latin America confirms that one in four firms ${ }^{4}$ cut back on innovation projects, showing significantly decreased investments in innovation during the 2008-2009 global crisis (Paunov, 2012).

Various national and supranational industrial and entrepreneurship policy frameworks (e.g. European Commission, 2010; MINPO, 2013) consider highly innovative SMEs the foundation of a national economy's competitiveness. Although, according to Schumpeter (1939), innovations are not driven by patterns of

3 In terms of share of turnover invested in innovation.

4 The average size of a firm is 65 employees. economic activity but, rather, technology and science influence entrepreneurial activity and consequently the business cycle, Rammer and Schubert (2016) indicate that the potential threat of SMEs starting to pull out of innovation would cause the economy to become substantially more reliant on a set of established large companies. Given the fact that a recession has a negative impact on industries more reliant on external finance (Moore and Mirzaei, 2016), it appears that the primary criterion for lending institutions is the size of the firm. Accordingly, limited access to investment capital surely destimulates economic growth and the capability of creating new jobs for micro and small businesses (Cowling et al., 2012). In conclusion, smaller firms tend to be more vulnerable due to economic cycles and fluctuations (Gertler and Gilchrist, 1994; Kangasharju, 2000; Hardwick and Adams, 2002; Fort et al., 2013), with an economic recession hitting them harder than larger firms (Bugamelli et al., 2009; Fort et al., 2013; Siemer, 2014). Since choices about innovation activities display a strong level of dependency, these tendencies could easily turn permanent (Rammer and Schubert, 2016).

Higson et al. $(2002,2004)$ analyzed firm-level crosssectional dynamics during the business cycle. These authors found firm growth distribution to be increasingly leptokurtic and skewed during recession. In line with these findings, Holly et al. (2012) showed the left side of growth rate distribution to be more responsive to a recession; in other words, it has stronger comovement. However, during a recession, the left side of growth rate distribution becomes thicker, while the right side becomes thinner. In other words, during recession the probability mass, left of the modal value of the growth rate distribution, grows, while the probability mass on the right side shrinks. Even while the right side of the distribution is getting smaller during an economic crisis, there are still good opportunities for the entrepreneurial sector (Barlett, 2008), especially for those firms that can identify the changes in the market and react promptly (Hodorogel, 2009). This is in line with Coad and Hölzl (2012) who conclude that even during a recession in a declining industry, there will always be some firms growing fast and others simultaneously experiencing rapid decline. Geroski (1993) gives his view of why the right side of growth rate distribution should be smaller; namely, regardless of whether a firm is innovative or not, it can prosper during an expansion, but only a few of the more innovative firms can continue to do so when the going gets tough, thus implying that a recession should lead to the growth of fewer firms during the recession period. Taking into account the literature review and arguments presented, it can be stated 
that the recession period has varying effects on firm dynamics. Therefore, we can hypothesize that in our sample the left tail of growth rates distribution will be thicker and the right tail will be thinner as a recession unfolds. Moreover, we can assume that the left tail of the growth rate distribution of micro/small firms will be thicker than the left tail of medium/large firms as a recession unfolds, in parallel with the presumption of a thinner right tail of micro/small firms compared with medium/large counterparts.

\section{TECHNOLOGICAL INTENSITY AND INDUSTRY DYNAMICS DURING A RECESSION}

Innovation undoubtedly drives economic development. It has clearly emerged that, with regard to innovation investment, the crisis has not been of the same magnitude across all European countries. Filippetti and Archibugi (2011) have shown that the most negatively affected by the downturn were those EU New Member States with weaker National Systems of Innovation (NSI), which were catching up over the 2006-2008 period. Conversely, Moore and Mirzaei (2016) found that low and lower-middle-income countries tend to be less affected by the crisis. In the process of rebuilding after the recessionary period, it was assumed that manufacturing would play a leading role (Pisano and Shih, 2009). However, Pisano and Shih (2009) claim that the focus of attention was not on manufacturing as a whole, but rather on a specific subcategory of manufacturing, namely high-tech industries. According to Hatzichronoglou (1996), highly technology-intensive firms innovate more and win new markets, using resources more productively and generally offering higher remuneration to the employees. In line with this assertion, from an EU policy perspective (European Commission, 2008; 2010), promoting high-tech industries through research and development (R\&D) investments is regarded as crucial to securing a competitive manufacturing industry. This reasoning has been questioned by a growing literature on the development of low-tech manufacturing, which emphasizes that non-R\&D-intensive industries comprise the majority of economic activity and retain significant importance in European countries (Hansen and Winther, 2011; Hirsch-Kreinsen, 2008; Kaloudis et al., 2005). Before the 2008 economic crisis, lowtech firms contributed approximately 55 per cent of the value added of total manufacturing in the EU-25 (European Commission, 2011).

The levels of performance of high-tech sectors and low-tech sectors are highly interrelated and interdependent. Low-tech sectors are quite technology-intensive, because they are significant users of the output from high-technology in their production process (Hirch-Kreisnen and Bender, 2006; Hansen and Winther, 2011; Czarnitzki and Thorwarth, 2012). However, it should be made clear that firms from low-tech sectors are not passively waiting to be outcompeted by firms from low-cost countries, but employ various strategies to remain competitive (Hirsch-Kreinsen, 2008). Moreover, the labor-intensive low-tech firms of yesterday are gradually being replaced by low-tech firms focusing on increasing investments in highly-skilled labor, advanced machinery and even R\&D. The implementation of new technologies, together with incremental innovation and a focus on high value-added niche markets, has become the key strategy of low-tech firms (Hansen and Winther, 2014). However, does the core of traditional manufacturing sectors still consist of generally small Supplier-dominated firms, as Pavitt (1984) argues, characterized by mature process technologies with weak in-house R\&D and engineering capabilities? Protogerou et al. (2013) presume low-tech markets are generally mature and slow-growing, with the high level of price competition forcing firms to focus on technology upgrades and improvements in processes, rather than on innovative projects. Accordingly, sectors and companies in low-tech markets have difficulties in producing extreme novelty because their technological knowledge and skills are cornered in by well-established technological trajectories (HirschKreinsen and Schwinge, 2011). As external resources become scarce and limited during a recessionary period, firms are forced to place reliance on internal capabilities and strategic reserves. Hence, if the innovation process does indeed transform the internal capabilities of firms (habitually, strongly concentrated in high-tech industries), then it would be interesting to see the economic effects of this transformation during periods of adversity. Finally, the review of the literature suggests that technological intensity and sector characteristics should play a substantial role in determining the rate of the growth of firms. Accordingly, we expect that in a recessionary economic environment both tails of high-tech sectors will differ relative to low-tech sectors: high-tech sectors will have a thinner left tail and thicker right tail relative to that of low-tech sectors. That difference should become even more pronounced as the recession unfolds.

\section{DATA}

Based on the technology intensity of industries measured in terms of R\&D intensity, the OECD (1994, 
2003) and Hatzichronoglou (1997) has suggested dividing manufacturing into four groups. The R\&Dintensity indicator measures the ratio of $R \& D$ expenditure to the turnover of a company or to the output value of an industry. By means of this indicator, industries with an R\&D intensity of more than 5 per cent on average are characterized as 'high-tech', those with an R\&D intensity between 3 and 5 per cent, as 'medium-hightech', those with an R\&D intensity between 3 and 0.9 per cent are classified as 'medium-low-tech' and those with an R\&D intensity below 0.9 per cent as 'low-tech' (Bender, 2004; Hirsch-Kreinsen et al., 2006). In this study, we follow the approach by Von Tunzelmann and Acha (2005) and Hirsch-Kreinsen et al. (2006), where the term 'low-tech manufacturing' refers to both low and medium-low-technology (LMT) sectors and 'hightech manufacturing' (HMT) refers to high and medium-high-tech sectors. We use the Accounting Act ${ }^{5}$ firm size definition to classify small, medium and large firms, which is in line with the European Commission (2003). Firm size and growth rate distributions were measured using annual data from the Financial Agency (FINA) ${ }^{6}$. Croatian statistics encompasses and covers all firms in the entire economy; all size classes, from the smallest firms without any employees to the largest firms; all legal forms, from simple limited liability companies to partnerships (limited, unlimited and silent); and all industries, classified by activities in line with the NKD 2007, which is directly comparable to the NACE Rev. 2 classification. Consequently, the Annual Financial Statements Registry is a central source of information on the business performance and financial position of legal entities that are subject to income taxation.

The data series of manufacturing industries were transformed into real terms by deflating with the Industrial Producer Price Index $(\mathrm{PPI})^{7}$ presented at

5 The Accounting Act and indicators set out on the last day of the fiscal year proceeding the fiscal year for which financial statements are drawn.

(1) Small entrepreneurs are those that do not exceed any two of the following conditions: total assets of HRK 32,500,000.00; revenue $65,000,000.00$; average number of employees in the course of the financial year 50 .

(2) Medium-sized entrepreneurs are those that exceed any two of the conditions referred to in paragraph (1), but do not exceed two of the following conditions: total assets of HRK 130,000,000.00; revenue 260,000,000.00; average number of employees 250 .

(3) Large entrepreneurs are those which exceed any two of the conditions referred to in paragraph (2).

6 All Croatian companies are obliged to submit their annual financial statements to the Financial Agency (FINA) for the purpose of public disclosure by 30 June of the following year.

7 Industrial producer price indices on domestic market, according to MIGs 2009 and NKD 2007 divisions - Manufacturing - Croatian Bureau of Statistics (DZS). the constant prices of a referent year $(2005=100)$. In line with the conditions of Mansfield's (1962) second demarcation, Audretsch and Mahmood (1994) and Watson (2012), the data set covers all Croatian limited liability and joint-stock firms in the manufacturing industries that were active, i.e. survived, through the whole observed recessionary period from 2008 to 2013. Following lootty et al. (2014), productivity growth is mostly driven by the performance of survival firms. In terms of statistical relevance, we consider that a balanced panel is a more reliable choice, as a complete panel comprises all observations for each individual measured at the same time points, i.e. it is composed only of firms that are present both at the beginning and at the end of the observed period. Obviously, the years leading to the entry and exit of particular firms strongly affect both tail distribution and represent industry dynamics more unrealistically. Furthermore, the approach of taking a balanced panel is rather usual in the literature (e.g. Bottazzi and Secchi, 2006; Bottazzi et al., 2011; Lunardi et al., 2014), with the addition of criteria for dropping outliers that are rather low (sometimes at 50\%). The final sample encompassed 5,762 firms observed across six years, creating a balanced panel data of 23,048 observations. Also, 5,334 or $92.57 \%$ of the firms were classified as small, $5.72 \%$ as medium-sized, and the remaining $1.70 \%$ as large firms. Concerning total GDP, the contribution of the Croatian manufacturing industry in the observed period varies around $12 \%$, and the share in total employment is around 17\% (DZS, 2016).

\section{METHODS}

We relied heavily on the work of Bottazzi and Secchi (2011). The measure of size is defined as a logarithm with base 10 of the firms' revenues.

$$
s_{i}(t)=\log _{10}\left(S_{i}(t)\right)
$$

Following the work of Holly et al. (2012), the growth rate of the firm $i$ is defined as the difference between firm $i$ 's size at time $t$ and its size at time $t-1$.

$$
g_{i}(t)=s_{i}(t)-s_{i}(t-1)
$$

We used the Binned Kernel Density Estimate to analyze the distributions of firm size and growth rate. This estimate can be simply described as a smoothed version of the histogram (Bottazzi et al., 2011).

$$
f(x, t ; h)=\frac{1}{n h} \sum_{i=1}^{n} K\left(\frac{x-s_{i}(t)}{h}\right)
$$

where $s_{1}(t) \ldots s_{n}(t)$ are the firm-level observations. Parameter $h$ (bandwidth) controls the degree 
of smoothness of the density estimate, while $K$ represents the kernel density ${ }^{8}$. It should be noted that the literature finds the choice of $K$ as a problem of less importance (Guidoum, 2015). We follow previous work in industrial organization (e.g. Bottazzi et al., 2011; Cabral and Mata, 2003) and set the kernel function to always be the Gaussian density, although we also use the Epanechnikov density, which does not change the results. On the other hand, selecting the bandwidth $h$ is particularly important. Namely, if the choice of $h$ is too small, the estimator will be under-smoothed and thus have high volatility, while if it is too big, the estimator will be over-smoothed and will not represent the distribution one is trying to estimate. One of the reasons Stark (2008) describes choosing the bandwidth as a "black art" is the many different approaches to calculating it, 9 with no clear instructions on which approach is best (see Deng and Wickhman, 2011). We choose bandwidth parameter $h$ using the function density that follows Silverman's (1986) procedure in the statistical program R. ${ }^{10}$

To analyze whether distributions at the disaggregate level (NACE 3-digit) are well represented by the aggregate distribution we use the bimodality test. ${ }^{11}$ We apply Silverman's bootstrap test for multimodality with Hall-York's calibration (Hall and York, 2001). This test assesses the modality or the "bumps" in distributions (Xu et al., 2014; p. 175). Our $\mathrm{H}_{0}$ is that the number of modes is 1 ; therefore, if the $p$ values are lower than 0.05 , the analyzed distribution is unimodal; however, if the $p$ values are greater than 0.05 , the distribution has more than one mode. To analyze the upper tail of firm size distribution we use the concentration ratio. As we have a comprehensive dataset, the concentration

8 Some frequent kernel functions are: Gaussian, Epanechnikov, Uniform, Triangular, Triweight, Tricube, Biweight and Cosine.

9 E.g. Silverman (1986) elaborates on the following: subjective choice; reference to a standard distribution; least-squares crossvalidation; likelihood cross-validation; the test graph method and internal estimation of the density roughness. Guidoum (2015) elaborates on optimal bandwidth with asymptotic mean integrated squared error; maximum likelihood cross-validation; unbiased cross-validation; biased cross-validation; complete cross-validation; modified cross-validation and trimmed cross-validation.

$10 \mathrm{R}$ version 3.3.0., package stats, function density

11 We analyze the growth rate distributions at NACE 2-digit level and firm size distribution at NACE 3-digit level. Quite a few NACE 3-digit sectors did not have enough observations for the analysis of growth rate distributions with asymmetric exponential power family of densities. For this reason, the analysis of growth rate distributions was undertaken at a more aggregate NACE 2-digit level. However, this was not an issue for the analysis of firm size distributions and in order to provide more meaningful information (e.g. on industry sectors' concentration ratios) we undertake the analysis of firm size distributions at NACE 3-digit level. ratio is defined as the market share (proxy is revenues) of the four largest firms in a NACE 3-digit sector.

$$
d_{n}^{4}(t)=\frac{C_{4}}{C_{n}}, t=2008, \ldots, 2013
$$

where $C_{4}$ is the sum of the market shares of the top four firms in a particular sector, while $C_{n}$ is the total market share of our balanced samples ${ }^{12}$ within a particular NACE 3-digit sector in the database. It should be highlighted that we are analyzing concentration ratios of only those firms that were active three years prior to the recession and only those that survived the recession. In other words, we are analyzing only the long-living firm base and their changes in market power.

Finally, we used the Asymmetric Exponential Power (AEP) family of densities (see Bottazzi and Secchi, 2011) to analyze the growth rate distributions.

$$
f\left(x ; b_{l}, b_{r}, a_{l}, a_{r}, m\right)=\frac{1}{C} e^{-\left(\frac{1}{b_{l}}\left|\frac{x-m}{a_{l}}\right|^{b_{l}} \theta(m-x)+\frac{1}{b_{r}}\left|\frac{x-m}{a_{r}}\right|^{b_{r}} \theta(x-m)\right)}
$$

where $\theta(x)$ is the Heaviside theta function and the normalization constant $C$ reads:

$$
C=a_{l} b_{l}^{1 / b_{l}-1} \Gamma\left(1 / b_{l}\right)+a_{r} b_{r}^{1 / b_{r}-1} \Gamma\left(1 / b_{r}\right)
$$

The principal parameters of interest are the location parameter $m$, two scale parameters $\alpha_{l}$ and $\alpha_{r}$ as well as two shape parameters $b_{l}$ and $b_{r}$ (where $l$ stands for left and $r$ stands for right).

Analysis was conducted via the statistical program $\mathrm{R}$ and subbotools package in the Cygwin environment. ${ }^{13}$

\section{RESULTS}

\subsection{Aggregate properties}

This section encompasses the parametric and nonparametric statistical analysis of firm size distribution and firm dynamics considering aggregated and disaggregated data, i.e. all manufacturers as well as subsamples of micro and small, medium and large enterprises. Additional emphasis in the research was given to the low-tech and high-tech manufacturing sectors. To begin with, we explore the descriptive statistics of firm size and growth distribution on the aggregated and disaggregated levels (see Appendices 1 \& 2).

12 We analyze a balanced panel, which leaves out data on firm entry and exit.

13 We thank Giulio Bottazzi for making the program 'subbotools' available. Web page link:

http://cafim.sssup.it/ giulio/software/subbotools/ 
Considering firm size distribution, the mean is less than (to the left of) the median, indicating a negatively skewed distribution which corresponds with negative skewness (Table 1). Negative skewness can indicate (e.g. for a unimodal distribution) that the tail on the left side of the probability density function is potentially longer or fatter than the right side. A large positive kurtosis value implies leptokurtic distribution. Leptokurtic is a statistical distribution resulting in a higher peak and fatter tails than the curvature found in a normal distribution.

Kurtosis is more influenced by scores in the tails of a distribution than by scores in the center of a distribution (DeCarlo, 1967). Considering growth dynamics (Table 2), high kurtosis motivated us to investigate outliers. We found several outliers on the left and the right side of distribution, and while observing further "movement" after one year of exponential fall or growth, we decided to keep them in the sample as the realistic influencer of tail "heaviness". Regarding skewness, aggregated and disaggregated levels reflect volatility, which emphasizes the need for further analysis.

The left and right tails of the growth rate distribution at the aggregate manufacturing level are much thicker than the Laplace tails, which is in line with the previous work of Bottazzi et al. (2011), but different from the findings of Bottazzi et al. (2001), Bottazzi and Secchi (2003), Reichstein and Jensen (2005) or Duschl and Peng (2015). The reasons for such differences might lie partly in the sample analyzed, as our sample included micro firms, whereas many other papers exclude a significant number of micro firms (e.g. Reichstein and Jensen, 2005; Bottazzi et al., 2011; Duschl and Peng, 2015). Furthermore, two different patterns in the skewness of the manufacturing firms' growth rate distribution arise during recession at the left- and right-hand sides. For manufacturing firms, we observe that the left tail thickens as years spent in recession increase (Table 3). There is a clear sequential drop of the left shape parameter $\beta_{l}$ in the period 20092013 ( $\beta_{l}$ decreases from 0.6606 to 0.4556 ), while at the same time the left scale parameter $\alpha_{l}$ is more volatile $\left(\alpha_{l}\right.$ first decreases two years in a row and then increases two years in a row; but there is an overall upward movement). Therefore, when comparing manufacturing firms with negative growth rates across years, the more years an economy has spent in the recession, the greater the probability that it will see highdecline manufacturing firms. The pattern is very similar when one breaks down the analysis of growth rate

Table 1: Low-tech and high-tech sector descriptive statistics of $s(t)$ in different years

\begin{tabular}{|c|c|c|c|c|c|}
\hline \multicolumn{6}{|c|}{ Manufacturing - aggregate } \\
\hline Year & Mean & Median & SD & Skewness & Kurtosis \\
\hline 2008 & 6.26953 & 6.304563 & 0.9799182 & -0.6354091 & 6.021808 \\
\hline 2009 & 6.207508 & 6.23725 & 0.9771905 & -0.5064604 & 5.360391 \\
\hline 2010 & 6.137863 & 6.163307 & 0.9902855 & -0.3828825 & 4.692557 \\
\hline 2011 & 6.102147 & 6.12896 & 1.013209 & -0.4293702 & 4.907135 \\
\hline 2012 & 6.032132 & 6.075791 & 1.068023 & -0.5993477 & 5.235905 \\
\hline 2013 & 5.992251 & 6.051967 & 1.127783 & -0.7622065 & 5.562448 \\
\hline \multicolumn{6}{|c|}{ High-tech sectors - aggregate } \\
\hline 2008 & 6.364792 & 6.39033 & 1.001704 & -0.4381354 & 5.13264 \\
\hline 2009 & 6.29188 & 6.315677 & 1.022065 & -0.555275 & 5.484447 \\
\hline 2010 & 6.243579 & 6.260734 & 0.9999699 & -0.1691724 & 4.046378 \\
\hline 2011 & 6.209594 & 6.212173 & 1.026665 & -0.2642268 & 4.248362 \\
\hline 2012 & 6.1456 & 6.18867 & 1.079524 & -0.4380452 & 4.470321 \\
\hline 2013 & 6.117755 & 6.153674 & 1.129649 & -0.6597026 & 5.228961 \\
\hline \multicolumn{6}{|c|}{ Low-tech sectors - aggregate } \\
\hline 2008 & 6.247738 & 6.287057 & 0.9736657 & -0.691006 & 6.242291 \\
\hline 2009 & 6.188224 & 6.212326 & 0.9657201 & -0.5015346 & 5.332516 \\
\hline 2010 & 6.113697 & 6.143598 & 0.9865764 & -0.4376174 & 4.832619 \\
\hline 2011 & 6.07754 & 6.100079 & 1.008603 & -0.4740979 & 5.060479 \\
\hline 2012 & 6.006205 & 6.050226 & 1.063797 & -0.6430537 & 5.416232 \\
\hline 2013 & 5.963495 & 6.020504 & 1.125508 & -0.7907447 & 5.645015 \\
\hline
\end{tabular}

Note: Size measured in terms of total sales. 
Table 2: Low-tech and high-tech sectors descriptive statistics of $\mathrm{g}(\mathrm{t})$ in different years

\begin{tabular}{|c|c|c|c|c|c|}
\hline \multicolumn{6}{|c|}{ Manufacturing - aggregate } \\
\hline Year & Mean & Median & SD & Skewness & Kurtosis \\
\hline 2009 & -0.06063243 & -0.04720485 & 0.3982013 & 2.828027 & 77.77032 \\
\hline 2010 & -0.0729732 & -0.0493011 & 0.3954355 & 0.8830619 & 54.16745 \\
\hline 2011 & -0.04313447 & -0.022365 & 0.3619197 & -1.844012 & 43.04946 \\
\hline 2012 & -0.06962248 & -0.03358427 & 0.4226338 & -2.07218 & 43.16368 \\
\hline 2013 & -0.05295978 & -0.005231584 & 0.5193874 & -2.374487 & 37.54963 \\
\hline \multicolumn{6}{|c|}{ High-tech sectors - aggregate } \\
\hline 2009 & -0.07296 & -0.04884 & 0.3298517 & -0.1540847 & 53.44401 \\
\hline 2010 & -0.05020 & -0.04728 & 0.3679236 & 3.723896 & 62.22807 \\
\hline 2011 & -0.03861 & -0.02018 & 0.3040071 & -3.816005 & 46.54264 \\
\hline 2012 & -0.06602 & -0.02898 & 0.4190442 & -1.392038 & 38.49361 \\
\hline 2013 & -0.03602 & -0.01012 & 0.4604368 & -2.607384 & 41.44507 \\
\hline \multicolumn{6}{|c|}{ Low-tech sectors - aggregate } \\
\hline 2009 & -0.05781 & -0.04708 & 0.4122256 & 3.143023 & 78.1172 \\
\hline 2010 & -0.07818 & -0.04992 & 0.4013184 & 0.3887274 & 52.57042 \\
\hline 2011 & -0.04417 & -0.02258 & 0.373944 & -1.582887 & 41.78391 \\
\hline 2012 & -0.07045 & -0.03514 & 0.4234893 & -2.22231 & 44.17529 \\
\hline 2013 & -0.056840 & -0.004238 & 0.5319451 & -2.324353 & 36.60775 \\
\hline
\end{tabular}

Table 3: Maximum likelihood parameter estimates of the AEP parameters for manufacturing firms 2009-2013

\begin{tabular}{|c|c|c|c|c|c|c|}
\hline NACE class & $\beta_{l}$ & $\beta_{r}$ & $\alpha_{l}$ & $\alpha_{r}$ & $m$ & $L L$ \\
\hline $\begin{array}{l}\text { Manufacturing aggregate } \\
2009\end{array}$ & $\begin{array}{c}0.6606 \\
(0.0167)\end{array}$ & $\begin{array}{c}0.5196 \\
(0.0127)\end{array}$ & $\begin{array}{c}0.1424 \\
(0.0031)\end{array}$ & $\begin{array}{c}0.109 \\
(0.0029)\end{array}$ & $\begin{array}{l}-0.0094 \\
(0.0004)\end{array}$ & -0.1716 \\
\hline $\begin{array}{l}\text { Manufacturing aggregate } \\
2010\end{array}$ & $\begin{array}{c}0.5807 \\
(0.0142)\end{array}$ & $\begin{array}{c}0.5149 \\
(0.0127)\end{array}$ & $\begin{array}{c}0.1378 \\
(0.0031)\end{array}$ & $\begin{array}{c}0.1042 \\
(0.0028)\end{array}$ & $\begin{array}{l}-0.0217 \\
(0.0003)\end{array}$ & -0.1619 \\
\hline $\begin{array}{l}\text { Manufacturing aggregate } \\
\qquad 2011\end{array}$ & $\begin{array}{c}0.5404 \\
(0.0130)\end{array}$ & $\begin{array}{c}0.5746 \\
(0.0147)\end{array}$ & $\begin{array}{c}0.1298 \\
(0.0031)\end{array}$ & $\begin{array}{c}0.1081 \\
(0.0026)\end{array}$ & $\begin{array}{l}-0.0153 \\
(0.0005)\end{array}$ & -0.1784 \\
\hline $\begin{array}{l}\text { Manufacturing aggregate } \\
\qquad 2012\end{array}$ & $\begin{array}{c}0.5032 \\
(0.0118)\end{array}$ & $\begin{array}{c}0.5257 \\
(0.0132)\end{array}$ & $\begin{array}{c}0.1368 \\
(0.0033)\end{array}$ & $\begin{array}{c}0.103 \\
(0.0027)\end{array}$ & $\begin{array}{l}-0.0200 \\
(0.0001)\end{array}$ & -0.1335 \\
\hline $\begin{array}{l}\text { Manufacturing aggregate } \\
2013\end{array}$ & $\begin{array}{c}0.4558 \\
(0.0104)\end{array}$ & $\begin{array}{c}0.497 \\
(0.0124)\end{array}$ & $\begin{array}{c}0.1527 \\
(0.0039)\end{array}$ & $\begin{array}{c}0.1136 \\
(0.0030)\end{array}$ & 0.0052 & 0.0056 \\
\hline
\end{tabular}

distribution to micro/small and medium/large manufacturing firms (Table 4). The main difference is the higher magnitude of $\beta_{l}$ decline among medium/large sized manufacturing firms. Intuitively, the reasons for such a sequential drop can be found in the phenomenon of recession. Namely, recession is characterized by a drop in demand and a drop in investments; as an economy spends more time in recession, consumption further declines, and this signals information to the economic agents interpreted as lower expected profits. Fueled with this information, economic agents are resistant to take risks and invest, thus experiencing further sales declines.

As opposed to the left side of the manufacturing firms' growth rate distribution, where a clear sequencing of $\beta_{l}$ is observed, the right shape parameter is more volatile. Namely, $\beta_{r}$ slightly drops in 2010 , followed by an increase in 2011, and then two sequential decreases in 2012 and 2013. However, in the period 2009-2013 there is an overall decrease of the right shape parameter $\beta_{r}$ (from 0.5196 to 0.4970 ), while the right scale parameter $\alpha_{r}$ is quite stable (between 0.10 and 0.11 ). Although parameters are somewhat volatile, as the recession unfolds there is a slight increase in the probability for an economy to experience highgrowth manufacturing firms. However, it should be said that, when comparing the left and right-hand side of the distribution, it is evident that a change of higher magnitude appears as the recession unfolds within the group of declining firms. When analyzing micro/small and medium/large manufacturing firms, the pattern of the change in $\beta_{r}$ is the same for micro/ small firms, but not for medium/large firms. Namely, the medium/large manufacturing firms' $\beta_{r}$ is volatile, but it overall increases as the recession unfolds. Therefore, there is a slight decrease in the probability 
that an economy will see high-growth medium/large manufacturing firms.

For manufacturing firms in low-tech sectors, we observe that the left tail thickens as years spent in the recession increase (Table 5). There is a clear sequential drop of the left shape parameter $\beta_{l}$ in the period 2009-2013 ( $\beta_{l}$ decreases from 0.6468 to 0.4578 ), while at the same time the left scale parameter $\alpha_{l}$ is more volatile, although overall there is upward movement. Therefore, when comparing manufacturing firms from

Table 4: Maximum likelihood parameter estimates of the AEP parameters for micro/small and medium/large manufacturing firms 2009-2013

\begin{tabular}{|c|c|c|c|c|c|c|}
\hline NACE class & $\beta_{l}$ & $\beta_{r}$ & $\alpha_{l}$ & $\alpha_{r}$ & $m$ & $L L$ \\
\hline $\begin{array}{l}\text { Manufacturing micro \& small } \\
\qquad 2009\end{array}$ & $\begin{array}{c}0.647 \\
(0.0174)\end{array}$ & $\begin{array}{c}0.5371 \\
(0.0142)\end{array}$ & $\begin{array}{c}0.1476 \\
(0.0034)\end{array}$ & $\begin{array}{c}0.1137 \\
(0.0031)\end{array}$ & $\begin{array}{l}-0.0151 \\
(0.0006)\end{array}$ & -0.1266 \\
\hline $\begin{array}{l}\text { Manufacturing micro \& small } \\
\qquad 2010\end{array}$ & $\begin{array}{c}0.5889 \\
(0.0153)\end{array}$ & $\begin{array}{c}0.5038 \\
(0.0130)\end{array}$ & $\begin{array}{c}0.1468 \\
(0.0035)\end{array}$ & $\begin{array}{c}0.1109 \\
(0.0032)\end{array}$ & $\begin{array}{l}-0.0215 \\
(0.0002)\end{array}$ & -0.1023 \\
\hline $\begin{array}{l}\text { Manufacturing micro \& small } \\
\qquad 2011\end{array}$ & $\begin{array}{c}0.5218 \\
(0.0130)\end{array}$ & $\begin{array}{c}0.5998 \\
(0.0164)\end{array}$ & $\begin{array}{c}0.1368 \\
(0.0035)\end{array}$ & $\begin{array}{c}0.1178 \\
(0.0030)\end{array}$ & $\begin{array}{l}-0.0296 \\
(0.0004)\end{array}$ & -0.1173 \\
\hline $\begin{array}{l}\text { Manufacturing micro \& small } \\
\qquad 2012\end{array}$ & $\begin{array}{c}0.5067 \\
(0.0125)\end{array}$ & $\begin{array}{c}0.5307 \\
(0.0141)\end{array}$ & $\begin{array}{c}0.1474 \\
(0.0038)\end{array}$ & $\begin{array}{c}0.111 \\
(0.0030)\end{array}$ & $\begin{array}{l}-0.0227 \\
(0.0002)\end{array}$ & -0.0622 \\
\hline $\begin{array}{l}\text { Manufacturing micro \& small } \\
2013\end{array}$ & $\begin{array}{c}0.4616 \\
(0.0112)\end{array}$ & $\begin{array}{c}0.4973 \\
(0.0131)\end{array}$ & $\begin{array}{c}0.1656 \\
(0.0045)\end{array}$ & $\begin{array}{c}0.1225 \\
(0.0034)\end{array}$ & 0.0052 & 0.0816 \\
\hline $\begin{array}{l}\text { Manufacturing medium \& large } \\
2009\end{array}$ & $\begin{array}{c}1.27 \\
(0.1063)\end{array}$ & $\begin{array}{c}0.3864 \\
(0.0269)\end{array}$ & $\begin{array}{c}0.1343 \\
(0.0068)\end{array}$ & $\begin{array}{c}0.0936 \\
(0.0117)\end{array}$ & 0.0431 & -0.6350 \\
\hline $\begin{array}{l}\text { Manufacturing medium \& large } \\
\qquad 2010\end{array}$ & $\begin{array}{c}0.9078 \\
(0.0833)\end{array}$ & $\begin{array}{c}0.7639 \\
(0.0704)\end{array}$ & $\begin{array}{c}0.0846 \\
(0.0055)\end{array}$ & $\begin{array}{c}0.0667 \\
(0.0046)\end{array}$ & $\begin{array}{l}-0.0064 \\
(0.0043)\end{array}$ & -0.8186 \\
\hline $\begin{array}{l}\text { Manufacturing medium \& large } \\
\qquad 2011\end{array}$ & $\begin{array}{c}0.7904 \\
(0.0677)\end{array}$ & $\begin{array}{c}0.6266 \\
(0.0502)\end{array}$ & $\begin{array}{c}0.0731 \\
(0.0047)\end{array}$ & $\begin{array}{c}0.0639 \\
(0.0046)\end{array}$ & $\begin{array}{c}0.0187 \\
(0.0021)\end{array}$ & -0.8513 \\
\hline $\begin{array}{l}\text { Manufacturing medium \& large } \\
\qquad 2012\end{array}$ & $\begin{array}{c}0.6568 \\
(0.0537)\end{array}$ & $\begin{array}{c}0.8233 \\
(0.0747)\end{array}$ & $\begin{array}{c}0.0641 \\
(0.0045)\end{array}$ & $\begin{array}{c}0.0646 \\
(0.0043)\end{array}$ & $\begin{array}{l}-0.0253 \\
(0.0025)\end{array}$ & -0.9267 \\
\hline $\begin{array}{l}\text { Manufacturing medium \& large } \\
\qquad 2013\end{array}$ & $\begin{array}{c}0.6713 \\
(0.0555)\end{array}$ & $\begin{array}{c}0.6076 \\
(0.0504)\end{array}$ & $\begin{array}{c}0.0718 \\
(0.0050)\end{array}$ & $\begin{array}{c}0.0594 \\
(0.0045)\end{array}$ & $\begin{array}{c}0.0206 \\
(0.0016)\end{array}$ & -0.8404 \\
\hline
\end{tabular}

Table 5: Maximum likelihood parameter estimates of the AEP parameters for the firms in the low-tech and high-tech sectors 2009-2013

\begin{tabular}{|c|c|c|c|c|c|c|}
\hline NACE class & $\beta_{l}$ & $\beta_{r}$ & $\alpha_{l}$ & $\alpha_{r}$ & $m$ & $L L$ \\
\hline $\begin{array}{l}\text { Low-tech aggregate } \\
2009\end{array}$ & $\begin{array}{c}0.6468 \\
(0.0181)\end{array}$ & $\begin{array}{c}0.5149 \\
(0.0138)\end{array}$ & $\begin{array}{c}0.1389 \\
(0.0034)\end{array}$ & $\begin{array}{c}0.1099 \\
(0.0032)\end{array}$ & $\begin{array}{l}-0.0127 \\
(0.0003)\end{array}$ & $\begin{array}{c}0.6468 \\
(0.0181)\end{array}$ \\
\hline $\begin{array}{l}\text { Low-tech aggregate } \\
2010\end{array}$ & $\begin{array}{c}0.5682 \\
(0.0153)\end{array}$ & $\begin{array}{c}0.514 \\
(0.0141)\end{array}$ & $\begin{array}{c}0.1392 \\
(0.0035)\end{array}$ & $\begin{array}{c}0.1021 \\
(0.0030)\end{array}$ & $\begin{array}{l}-0.0217 \\
(0.0003)\end{array}$ & -0.1578 \\
\hline $\begin{array}{l}\text { Low-tech aggregate } \\
2011\end{array}$ & $\begin{array}{c}0.532 \\
(0.0141)\end{array}$ & $\begin{array}{c}0.5651 \\
(0.0160)\end{array}$ & $\begin{array}{c}0.1304 \\
(0.0035)\end{array}$ & $\begin{array}{c}0.108 \\
(0.0029)\end{array}$ & $\begin{array}{l}-0.0155 \\
(0.0004)\end{array}$ & -0.1689 \\
\hline $\begin{array}{l}\text { Low-tech aggregate } \\
2012\end{array}$ & $\begin{array}{c}0.4992 \\
(0.0129)\end{array}$ & $\begin{array}{c}0.537 \\
(0.015)\end{array}$ & $\begin{array}{c}0.1371 \\
(0.0037)\end{array}$ & $\begin{array}{c}0.104 \\
(0.0029)\end{array}$ & -0.0244 & -0.1318 \\
\hline $\begin{array}{l}\text { Low-tech aggregate } \\
2013\end{array}$ & $\begin{array}{c}0.4578 \\
(0.0116)\end{array}$ & $\begin{array}{c}0.4827 \\
(0.0132)\end{array}$ & $\begin{array}{c}0.1559 \\
(0.0044)\end{array}$ & $\begin{array}{c}0.1124 \\
(0.0034)\end{array}$ & 0.01182 & 0.0203 \\
\hline $\begin{array}{l}\text { High-tech aggregate } \\
2009\end{array}$ & $\begin{array}{c}0.6909 \\
(0.0410)\end{array}$ & $\begin{array}{c}0.5672 \\
(0.0341)\end{array}$ & $\begin{array}{c}0.1529 \\
(0.0075)\end{array}$ & $\begin{array}{c}0.1045 \\
(0.0063)\end{array}$ & $\begin{array}{l}-0.0055 \\
(0.0017)\end{array}$ & -0.1710 \\
\hline $\begin{array}{l}\text { High-tech aggregate } \\
2010\end{array}$ & $\begin{array}{c}0.6779 \\
(0.0405)\end{array}$ & $\begin{array}{c}0.5154 \\
(0.0285)\end{array}$ & $\begin{array}{c}0.1344 \\
(0.0068)\end{array}$ & $\begin{array}{c}0.1149 \\
(0.0070)\end{array}$ & $\begin{array}{l}-0.0172 \\
(0.0008)\end{array}$ & -0.1864 \\
\hline $\begin{array}{l}\text { High-tech aggregate } \\
2011\end{array}$ & $\begin{array}{c}0.5268 \\
(0.0283)\end{array}$ & $\begin{array}{c}0.7477 \\
(0.0471)\end{array}$ & $\begin{array}{c}0.1278 \\
(0.0074)\end{array}$ & $\begin{array}{c}0.1206 \\
(0.0060)\end{array}$ & $\begin{array}{l}-0.0422 \\
(0.0011)\end{array}$ & -0.2228 \\
\hline $\begin{array}{l}\text { High-tech aggregate } \\
\qquad 2012\end{array}$ & $\begin{array}{c}0.4982 \\
(0.0271)\end{array}$ & $\begin{array}{c}0.4891 \\
(0.0278)\end{array}$ & $\begin{array}{c}0.134 \\
(0.00758)\end{array}$ & $\begin{array}{c}0.0992 \\
(0.0062)\end{array}$ & -0.0085 & -0.1446 \\
\hline $\begin{array}{l}\text { High-tech aggregate } \\
2013\end{array}$ & $\begin{array}{c}0.4716 \\
(0.0249)\end{array}$ & $\begin{array}{c}0.539 \\
(0.0307)\end{array}$ & $\begin{array}{c}0.1386 \\
(0.0083)\end{array}$ & $\begin{array}{c}0.1184 \\
(0.0068)\end{array}$ & -0.0119 & -0.0617 \\
\hline
\end{tabular}


low-tech sectors with negative growth rates across years, the more years an economy has spent in the recession, the greater the difference between negative growth rates across years. Among high-tech sectors, the same sequential drop is reported for $\beta_{l}$, while $\alpha_{l}$ is volatile but decreasing. In the case of a prolonged recession there are an increasing number of highdeclining firms and a higher magnitude of high decline in sales, which is linked to the performance of the entire economy. Declines in sales are the result of the decreased demand faced by firms and the high uncertainty of expected profits, which lead to lower investments that can be further enhanced with credit market imperfections. Given the interdependence of sectors in the economy, these slowdowns and declines in sales of all firms' sizes can be very harmful. Due to decreased demand, firms' unused capacity and inventories increase, thus revenues decrease. At the same time this also affects their suppliers and leads to a downward spiral. Following the demand decline, firms could cut back on employment and minimize expenditures for marketing and advertising, investments in research and development, stop acquiring new equipment, and halt new product development.

As opposed to the left side, where the clear sequencing of $\beta_{l}$ is observed, the right shape parameter of low-tech manufacturing firms is more volatile. Namely, $\beta_{r}$ slightly drops in 2010 , followed by an increase in 2011, and then two sequential decreases in 2012 and 2013. However, in the period 2009-2013 there is an overall decrease of the right shape parameter $\beta_{r}$ (from 0.5149 to 0.4827 ), while the right scale parameter $\alpha_{r}$ is quite stable (between 0.1021 and 0.1124 ) for low-tech sectors. On the other hand, the change of $\beta_{r}$ from high-tech manufacturing firms' growth rate distribution is more volatile, when compared with that of low-techs, while $\alpha_{r}$ is volatile (but overall increasing). However, it should be said that, when comparing the left and right hand side of the high-tech and low-tech distribution, change of a higher magnitude appears in the group of declining firms. Thus we observe heterogenous right tail change, which is driven by firms that managed to acquire some of the customers from declining firms, exploit new business opportunities in foreign markets, or successfully introduced innovations. Our analysis is explorative and identifying which growth triggers explain right tail change in different years is outside the scope of this research.

\subsection{Sectorial properties}

Following previous work in the field, for robustness we analyze growth rate distribution at a finer level, namely at the NACE 2-digit sectors (Appendix 3). Growth rate distributions survived disaggregation, in line with previous papers (Reichstein and Jensen, 2005; Bottazzi and Secchi, 2006; Bottazzi et al., 2011). In the high- and low-tech NACE 2-digit sectors, as was the case at the aggregate level, the growth rate distributions were mostly thicker than the Laplace. We also undertake the same analyses based on a different growth rate definition, that is, (( Size $\left.\left._{\mathrm{t}}-\mathrm{Size}_{\mathrm{t}-1}\right) / \mathrm{Size}_{\mathrm{t}-1}\right)$, although the results stay similar and do not change our conclusions ${ }^{14}$.

The change of $\beta_{l}$ at the high- and low-tech aggregate level had a clear sequential drop during the recession, which can be also seen when comparing the change of $\beta_{l}$ at the NACE 2-digit sectors. Namely, 3/4 high-tech sectors experienced a thickening of the left tail and only one a thinning of the left tail when comparing 2009 and 2013. In low-tech sectors, the left tail was thicker in $15 / 16$ cases and thinner in only one sector during the recession. Therefore, the change of $\beta_{l}$ as the recession unfolds at the aggregate level seems to hold also at a finer level. On the other hand, $\beta_{r}$ was volatile at the aggregate level of both high- and lowtech sectors but the movement showed an overall decrease. At the NACE 2-digit level, $\beta_{r}$ thickened in 2/4 high-tech sectors, while in $2 / 4$ high-tech sectors it became thinner when comparing the years 2009 and 2013. There was a thickening of $\beta_{r}$ in $11 / 16$ low-tech sectors and a thinning of the right tail in $5 / 16$ sectors. While there are differences, it can be stated that $\beta_{l}$ gets thicker as the recession unfolds, as does $\beta_{r}$; however, the empirical findings are less convincing for the right tail.

We also analyze firm size distribution at an even finer level, namely the NACE 3-digit sectors. Appendix 4 shows the mean size of sectors in 2008 (the year when the recession started) and in 2013 (the last year of our sample; the Republic of Croatia had been officially in a recession during the whole period 2008-2013). Out of the nine high-tech sectors analyzed, eight had a significant decrease in mean size, while only one had an increase. On the other hand, out of the 33 low-tech sectors analyzed, nine had an increase in mean size, while 24 sectors had a decrease.

With regard to the concentration ratios, both the high- and low-tech sectors vary greatly in concentration ratios, in line with the previous findings in the topic (Bottazzi et al., 2007; Bottazzi et al., 2011). In the high-tech sector the average concentration ratio in the 2008-2013 period varied from 0.2615 to 0.9333 , while in the low-tech sector it varied from 0.2570 to 0.9670 . When comparing 2008 and 2013, the concentration

14 Results are available upon request. 
ratios in high-tech sectors increased in 5 of the 9 sectors analyzed, 3 of the 9 sectors had a decrease, while 1 of the 9 remained the same. On the other hand, lowtech sectors featured an increase in the concentration ratios of the top four firms in 22 of 33 sectors, 4 of 33 sectors had a decrease in concentration ratio, while 7 of 33 remained the same. Acknowledging this is just a descriptive statistic, it seems the upper tail tends to be more concentrated as the recession unfolds, in line with Bottazzi et al. (2011).

Finally, a more robust statistic of firm size distribution, namely bimodality, is given in Appendix 4. The aggregate firm size distribution in most cases does not survive disaggregation, which is in line with previous work. However, modalities seem to change in some sectors as the recession unfolds. During the period analyzed, 6 of 9 high-tech sectors remained multimodal, while a change in modality appeared in 3 of 9 sectors. More precisely, firm size distributions in 2 of 9 sectors were unimodal in 2008, but became multimodal in 2013 after five years of recession. Also, in one high-tech sector, firm size distribution was initially multimodal, and then became unimodal. Fifteen of 33 low-tech sectors remained multimodal and 4 of 33 , unimodal. A change in modality was found in 14 of 33 sectors analyzed. Namely, in 2008, the firm size distribution of 9 of 33 low-tech sectors had a unimodal shape, while after five additional years in recession these nine sectors had a multimodal shape. On the other hand, 5 of 33 sectors had a multimodal shape in 2008 , leading to unimodal shapes in 2013. While we did not find a general empirical change of firm size distribution modes, we did, however, find that almost half of the low-tech sectors and one-third of the hightech sectors changed their firm size distribution modality as the recession unfolded. Why this happens is a puzzling question, and one which points to a clear direction for future research.

\section{DISCUSSION AND CONCLUSION}

Bottazzi and Secchi (2006) proposed a firm competition model with an upfront given number of business opportunities available to firms. These competing firms differ in the model, based on their previous success in exploiting opportunities, which gives them a higher possibility of exploiting new opportunities. This way, the authors theoretically explain the existence of a heavy tailed firm growth rate distribution. In a similar light, Cabral and Mata (2003) proposed their model of the evolution of firm size distribution, which asserted financial constraints as the primary force of this evolution. Both of these papers emerged following previous empirical contributions by authors in the field. We investigate the statistical regularities of industry dynamics in the manufacturing industry during a unique six-year recession period. The recession period is a very intriguing phenomenon because it represents an external shock to the firms' environment, forcing them to discover new ways of using current capabilities, routines or create new capabilities. While most firms can prosper in a growing and stable market, not everyone can prosper during an economic downturn. Ogawa and Tanaka (2013) found three shocks related to recession: demand, supply, and financial shocks. We investigate whether a possible mix of these shocks contributes to a change in firm distributions as the recession unfolds. That being said, our primary research interest was the nature of growth rate distribution during the recession at the aggregate and disaggregate levels, and was accompanied by an investigation of firm size distribution. Finally, given the differences in R\&D intensity and internal capabilities, we place special emphasis on the low-tech and high-tech manufacturing sectors, as proposed by the OECD classification.

On a general level, we confirm several findings previously established in the literature: that the aggregate firm size distribution does not survive disaggregation, the upper tail - concentration ratio varyies greatly, and that growth rate distributions are heavy tailed and survive disaggregation. We give further support to closing the question on the symmetry of the growth rate distribution tails; that is, the tails were not symmetric as initially proposed (Stanley et al., 1996; Bottazzi et al., 2001; Bottazzi and Secchi, 2003) but asymmetric (Reichstein and Jensen, 2005; Bottazzi et al., 2011). Lastly, the Laplace distribution is not the best approximation. In most cases the growth rate distribution tails were quite thicker than the Laplace distribution at the aggregate and disaggregate levels, which is similar to results found in the French manufacturing industry (Bottazzi et al., 2011) but also different from the results found on the sample of manufacturing industries in Italy (Bottazzi and Secchi, 2003), Denmark (Reichstein and Jensen, 2005), China (Duschl and Peng, 2015) or the publicly quoted manufacturing firms in the United States and the European Union (Lunardi et al., 2014). As was found by Reichstein and Jensen (2005), the right tail was thicker than the left tail at the beginning of the recession period; however, by the end of the period analyzed, the left tail was thicker than the right tail of the growth rate distribution.

The pervasive effect of recession led the left tail to diminish quite below the beta value of one. This holds true for the general sample of manufacturing firms 
and for the subsamples of micro and small, medium and large, low-tech, high-tech firms, and at the disaggregate level. Our results suggest that the more years an economy spends in recession, the greater the decline in the left tail, which is in line with the work of Holly et al. (2012) and the previous work of Higson et al. (2002, 2004). It should be highlighted that the strongest magnitude in decline of the left tail was among medium and large manufacturing firms. Holly et al. (2012) suggest that such left tail evolution is due to the higher financial constraints of those firms that have experienced sales decline, that is, firms with declining sales are less and less attractive to credit lenders as its years in the recession increase. These rapidly declining firms affect the left tail of the growth rate distribution, and thus the distribution becomes increasingly heavy-tailed. From an evolutionary perspective, it can be said that a recession necessitates a change in routines; if these are not successfully modified, a decline in revenue occurs, which then leads to reduced attractiveness for credit lenders, supporting a further negative spiral in firm performance. In addition, given that firms interact in the market, as suppliers, partners or just observers, these interactions lead to what Keynes calls animal spirits, supporting the bear market. Along this line, Holly et al. (2012; p.1) show that changes in growth rate distributions can act as a leading variable in explaining the business cylce and is an important propagator of business fluctuations. Future researchers are encouraged to tackle this question. To do so, a longer panel, including pre-recession and post-recession periods, will be necessary.

We now turn to the right tail of the growth rate distribution. The right tail is quite thicker than the Laplace, and its behavior paints a different picture when compared to the left tail. The manufacturing industry's right shape parameter is volatile but decreasing overall, similar to the subsample of micro and small firms, low-tech and high-tech sectors, and different from the subsample of medium and large firms, whose right shape parameter is volatile but increasing. The medium and large manufacturing firms differ from the rest of the sample not only in the right shape parameter but in the right width parameter as well. Thus, it seems that the recession has a different effect on medium and large firms from the right hand side of the firm growth rate distribution. Our results point to asymmetric microeconomic volatility during an economic downturn, in line with Holly et al. (2012). The left tail shows procyclical movement during the recession, sequentially decreasing during the whole recession period, which is accompanied by a volatile but overall increasing left width parameter, except in the case of medium and large firms.
Thus, there seems to be a kind of mechanism with a non-linear response to economic downturns. As the recession unfolds, there are an increasing number of small firms with high-growth rates and a decreasing number of medium and large firms with high-growth rates. Thus, the growth-opportunities for medium and large firms seem to be decreasing, while the opportunities for few innovative small firms are expanding. This is in line with the creative destruction proposed by Schumpeter's (1934). Future research on the business models of the medium and large firms and their vulnerability to external shocks are encouraged.

In light of the policy focus towards the high-tech sectors, we look at the growth rate distribution evolution of the subsample of the high-tech and lowtech manufacturing sectors. The left tail parameter had a similar change in both the low-tech and hightech sectors as a recession unfolded. However, the left width parameter had volatile but opposing overall movement. The high-tech sectors had an overall decrease in the left width parameter, implying that there were fewer firms on the left side of the modal growth rate as a recession unfolded. The right shape parameter was more volatile in high-tech sectors than in low-tech sectors, but the overall movement among these two was a decline in the right shape parameter. The right width parameter was somewhat stable in low-tech sectors, while it moved more upwardly in the high-tech sectors. This implies that the mass of firms at the right side of the modal growth rate experienced an upward trend within the high-tech sectors as a recession unfolded. Thus, it seems that high-tech sectors handle recessions slightly better. This may perhaps be attributed to growth mechanisms, such as learning processes or higher investment in innovation, i.e. research and development spending. Further research is needed to understand the policy measures that interfered during the recession in the high-tech and low-tech sectors.

Some policy implications have arisen from our research. Given that the longer the recession period the thicker the left tail, we may assert that, first, government policies should be more effective in the reallocation of resources from declining toward growth activities by fostering new business models, persuading banks to increase their lending, and in this way enable the mitigation of the impacts of the financial crisis. Second, looking to stabilize the economy and initiating rapid recovery, the policy framework should give stronger incentives for innovation in businesses of all sizes and in all sectors. Policymakers should promote high-tech industries, yet not without including and ameliorating their consciences over core laborintensive low-tech firms that are primarily non-R\&D 
technological innovators that use organizational and marketing innovation in order to compensate for an absence of R\&D activity. In times of crisis, owing to high sectoral interrelation and dependence, policymakers should efficiently stimulate a range of firms through competitiveness measures.

Further investigation is needed regarding the change in the firm-size distribution. We report the initial evidence of change in the modality of firm size distributions in the NACE 3-digit sector. Six years spent in recession pointed out several structural differences among different manufacturing sectors, very likely due to technological and organizational factors. Almost half of the sectors had a change, either from unimodal to multimodal firm size distributions or vice versa. Intuitively, it seems that some sectors tend toward the 'optimal size' of a firm in a sector, while in others multiple modes emerge. The questions that arise are why this is so and whether it could just be a statistical coincidence. Further research might delve deeper into the industry life-cycle, financial constraints, technological progress or capabilities in these sectors/firms to understand the economic regularities explaining unimodal or multimodal evolution. In our sample, the changes in modality were reported more frequently in the low-tech sectors, as opposed to high-tech sectors. These initial findings need additional empirical investigation. The Cabral and Mata (2003) model of the evolution of firm size distribution could be a starting point in explaining such modal changes in sectors. Finally, in line with previous work (Coricelli et al., 2012), concentration ratios increased in most of the sectors, and to a more pronounced degree in the low-tech rather than high-tech sectors, although this is far from conclusive.

\section{REFERENCES}

Aghion, P., \& Saint-Paul, G. (1998). Virtues of Bad Times, Interaction Between Productivity Growth and Economic Fluctuations. Macroeconomic Dynamics, 2(3), p. 322-344.

Akbar, S., Rehman, S., \& Ormrod, P. (2013). The impact of recent financial shocks on the financing and investment policies of UK private firms. International Review of Financial Analysis, 26(C), 59-70.

Audretsch, D. B., \& Mahmood, T. (1995). New firm survival: new results using a hazard function. The Review of Economics and Statistics, 77(1), p. 97-103.

Audretsch, D., Santarelli, E., \& Vivarelli, M. (1999). Start-up Size and Industrial Dynamics: Some Evidence from Italian Manufacturing. International Journal of Industrial Organization, 17, p. 965- 983.
Bai, C., Mao, J., \& Zhang, Q. (2014). Measuring market concentration in China: the problem with using censored data and its rectification. China Economic Review, 30, p. 432447, doi: http://doi.org/10.1016/j.chieco.2014.05.013

Bain, J. S. (1968). Industrial Organization. 2 nd edition. New York: John Wiley \& Sons, Inc.

Bakke, T.-E. (2009). Natural experiments in corporate investments and financing. Unpublished doctoral dissertation, University of Wisconsin - Madison.

Bartlett, D. (2008). Fallout of the Global Financial Crisis. Beijing: RSM International

Bender, G. (2004). Innovation in Low-tech-Considerations based on a few case studies in eleven European countries.

Bharadwaj, S. G., \& Varadarajan, R. (2005). Toward an Integrated Model of Business Performance, in Naresh K. Malhotra (ed.) Review of Marketing Research (1) Emerald Group Publishing Limited, pp. 207 - 244

Bottazzi, G. and Secchi, A. (2011) A new class of asymmetric exponential power densities with applications to economics and finance. Industrial and Corporate Change, 20, p. 991-1030.

Bottazzi, G., \& Secchi, A. (2003). Common properties and sectoral specificities in the dynamics of US manufacturing companies. Review of Industrial Organization, 23(3-4), p. 217-232.

Bottazzi, G., \& Secchi, A. (2006). Explaining the distribution of firm growth rates. The RAND Journal of Economics, 37(2), p. 235-256.

Bottazzi, G., Cefis, E., Dosi, G., \& Secchi, A. (2007). Invariances and diversities in the patterns of industrial evolution: Some evidence from Italian manufacturing industries. Small Business Economics, 29(1-2), 137-159.

Bottazzi, G., Coad, A., Jacoby, N., \& Secchi, A. (2011). Corporate growth and industrial dynamics: Evidence from French manufacturing. Applied Economics, 43(1), 103-116, doi: http://dx.doi.org/10.1080/00036840802400454

Bottazzi, G., Pirino, D., \& Tamagni, F. (2015). Zipf law and the firm size distribution: a critical discussion of popular estimators. Journal of Evolutionary Economics, 25, (3), p. 585-610, doi: 10.1007/s00191-015-0395-7

Bottazzi, G., Secchi, A., \& Tamagni, F. (2014). Financial constraints and firm dynamics. Small Business Economics, 42(1), 99-116.

Braun, M., \& Larrain, B. (2005). Finance and the Business Cycle: International, Inter-Industry Evidence. The Journal of Finance, 60 (3), p. 1097-1128, doi: 10.1111/j.1540-6261.2005.00757.x

Buca, A., \& Vermeulen, P. (2012). Corporate investment and bank-dependent borrowers during the recent financial crisis. Society for Economic Dynamics. 2012 Meeting Papers, Number 695.

Bugamelli, M., Cristadoro R., \& Zevi G. (2009). The international crisis and the Italian productive system: an 
analysis of firm-level data. Questioni di Economia $e$ Finanza (Occasional papers), 58. Banca d'Italia: Roma.

Caballero, R., \& Hammour, M. L. (1994). The Cleansing Effect of Recessions. American Economic Review, 84(5), p. 1350-68.

Cabral, L. (2000). Introduction to Industrial Organization, MIT Press.

Cabral, L., \& Mata, J. (2003). On the evolution of the firm size distribution: Facts and theory. The American Economic Review, 93(4), p. 1075-1090.

Caloghirou, Y., Protogerou, A., \& Tsakanikas, A. (2014). Exploring knowledge-intensive entrepreneurship in high-tech and low-tech manufacturing sectors: differences and similarities, in Knowledge-Intensive Entrepreneurship in Low-Tech Sectors: The Prospects of Traditional Economic Industries, H. Hirsch-Kreinsen and I. Schwinge (eds.), Edward Elgar Publishing, UK.

Calvo, J. L. (2006). Testing Gibrat's law for small, young and innovative firms. Small Business Economics, 26(2), p. 117123, doi: 10.1007/s11187-004-2135-5.

Campello, M., Graham, J. R., \& Harvey, C. R. (2010). The real effects of financial constraints: Evidence from a financial crisis. Journal of Financial Economics, 97(3), p. 470-487.

Chiang, Y. H., Tang, B. S., \& Leung, W.Y. (2001). Market structure of the construction industry in Hong Kong. Construction Management and Economics, 19(7), p. 675-687.

Christiano, L. J., Martin S. Eichenbaum, M. S., \& Trabandt, M. (2015). Understanding the Great Recession. American Economic Journal: Macroeconomics, 7(1), p. 110-67, doi: 10.1257/mac.20140104.

Coad, A., \& Hölzl, W. (2012). Firm growth: empirical analysis. In M. Dietrich \& J. Krafft (Eds.), Handbook on the economics and theory of the firm (pp. 324-338). Cheltenham: Edward Elgar Publishing Limited

Contini, B., \& Revelli, R. (1989). The relationship between firm growth and labor demand. Small Business Economics, 1 (3). p. 309-314.

Coricelli, F., Karadimitropoulou, A., \& Leon-Ledesma, M. (2012). A Disaggregate Characterisation of Recessions, Studies in Economics, School of Economics, University of Kent.

Cowling, M., Liu, W., \& Ledger, A. (2012). Small business financing in the UK before and after the financial crisis. International Small Business Journal, 30(7), p. 778-800.

Cowling, M., Liu, W., Ledger, A., \& Zhang, N. (2015). What really happens to small and medium-sized enterprises in a global economic recession? UK evidence on sales and job dynamics. International Small Business Journal. 33(5), p. 488-513. doi:10.1177/0266242613512513

Crosato L., Destefanis S., \& Ganugi P. (2014). Firm Size Distribution and Returns to Scale. Non-Parametric Frontier Estimates from Italian Manufacturing, in Innovation, Globalization and Firm Dynamics: Lessons for
Enterprise Policy, Yilmaz, K., Ferragina, A.M., Taymaz, E. (Eds), Routledge Studies in the Modern World Economy.

Czarnitzki, D., \& Thorwarth, S. (2012). Productivity effects of basic research in low-tech and high-tech industries. Research Policy, 41, pp. 1555-1564.

Čaršimamović, V. N., Jankulov, S. I., \& Smirnov, I. (2013). PostCrisis Potential Output in the Western Balkans. South East European Journal of Economics and Business, 8(1), 1-11. doi: 10.2478/jeb-2013-0002

DeCarlo, L. T. (1997). On the meaning and use of kurtosis. Psychological Methods, 2, p.292-307.

Deng, H., \& Wickham, H. (2011). Density estimation in R. Electronic publication. Available at: http://www2.cs.uh. edu/ ceick/7362/T2-4.pdf. Accessed [12 April 2017]

Dosi, G., Lechevalier, S., \& Secchi, A. (2010). Interfirm heterogeneity: nature, sources and consequences for industrial dynamics. An introduction. Industrial and Corporate Change, 19, pp.1867.

Dosi, G., Marsili, O., Orsenigo, L., \& Salvatore, R. (1995). Learning, market selection and the evolution of industrial structures. Small Business Economics, 7(6), p. 411-436.

Duschl, M. (2014). Regional resilience and fat tails-a stochastic analysis of firm growth rate distributions of German regions. Working Papers on Innovation and Space Vol. 01.14, Marburg.

Duschl, M., \& Peng, S. S. (2015). The patterns of Chinese firm growth: a conditional estimation approach of the asymmetric exponential power density. Industrial and Corporate Change, 24(3), 539-563.

DZS (2016). Statistical Yearbook of the Republic of Croatia 2016. Zagreb: Croatian Bureau of Statistics, Available at https://www.dzs.hr/Hrv_Eng/ljetopis/2016/sljh2016.pdf [Accessed 23 September 2017].

Efendic, A., \& Pugh, G. (2007). Institutions and Economic Performance: An overview of empirical research with the main focus on Transition Economies. South East European Journal of Economics and Business, 2(1), p. 2530. doi: 10.2478/v10033-007-0012-2

European Commission. (2003). Commission's Recommendation 2003/361/EC of 6 May 2003. Brussels: European Commission.

European Commission. (2008). A More Research-Intensive and Integrated European Research Area. Brussels: European Commission.

European Commission (2010). EU Manufacturing Industry: What are the Challenges and Opportunities for the Coming Years? Available at http://ec.europa.eu/enterprise/policies/industrial-competitiveness/economiccrisis/files/eu_manufacturing_challenges_and_opportunities_en.pdf [Accessed 23 May 2016].

European Commission. (2011). European Industrial Structure: Trends and Performances. Available at http:// ec.europa.eu/enterprise/newsroom/cf/_getdocument. cfm?doc_id57066 [Accessed 28 May 2016]. 
Farkas, B. (2013). Changes is in the European convergence model. WIIW Monthly Report, 2013(1), p. 14-19.

Farkas, B. (2017). Market economies of the Western Balkans compared to the Central and Eastern European model of capitalism. Croatian Economic Survey, 19(1), p. 5-36.

Filippetti, A., \& Archibugi, D. (2011). Innovation in times of crisis: National Systems of Innovation, structure, and demand. Research Policy, 40(2), p. 179-192, doi: 10.1016/j. respol.2010.09.001.

Fingleton, J. (2009). Competition policy in troubled times, in Mercato Concorrenza Regole, pp. 7-22, doi: $10.1434 / 29267$.

Flammer, C., \& loannou, I. (2015). The dog that didn't bark: long-term strategies in times of recession. Working paper, University of Western Ontario, London, ON.

Fort, T. C., Haltiwanger, J., Jarmin, R. S., \& Miranda J. (2013). How firms respond to business cycles: the role of firm age and firm size. NBER Working Papers 19134. Available at http://www.nber.org/papers/w19134. [Accessed 11 January 2017].

Fotopoulos, G., \& Giotopoulos, I. (2010). Gibrat's law and persistence of growth in Greek manufacturing, Small Business Economics, 35(2), p. 191-202.

Fujimoto, S., Ishikawa, A., Mizuno, T., \& Watanabe, T. (2011). A new method for measuring tail exponents of firm size distributions. Economics: The Open-Access, OpenAssessment E-Journal, 5, p. 2011-20, doi: 10.5018/economics-ejournal.ja.2011-20

Geels, F. W. (2013). The impact of the financial-economic crisis on sustainability transitions: Financial investment, governance and public discourse. Environmental Innovation and Societal Transitions, 6, 67-95. doi: 10.1016/j.eist.2012.11.004.

Geroski, P. A. (1993). Antitrust Policy Towards Cooperative R and D Ventures. Oxford Review of Economic Policy, 9(2), p. 58-71.

Geroski, P. A., \& Gregg, P. (1997). Coping with Recession. UK Company Performance in Adversity. Cambridge: Cambridge University Press.

Gertler, M., \& Gilchrist, S. (1994). Monetary Policy, Business Cycles, and the Behavior of Small Manufacturing Firms, The Quarterly Journal of Economics, 109(2), pp. 309-340.

Gibrat, R. (1931). Lesine'galite'se'conomiques. Paris: Librairie du Receuil Sirey

Gilchrist, S., \& Sim, J.W. (2007). Investment During The Korean Financial Crisis: A Structural Econometric Approach. Working Papers Series WP2007-001, Boston University Department of Economics.

Guidoum, A. C. (2015). Kernel Estimator and Bandwidth Selection for Density and its Derivatives. The kedd package. Available at: https://cran.r-project.org/web/packages/kedd/vignettes/kedd.pdf .[Accessed 12 April 2017]

Hall, P., \& York, M. (2001). On the calibration of Silverman's test for multimodality. Statistica Sinica, 11, p. 515-536.
Hansen, T., \& Winther, L. (2011). Innovation, regional development and relations between high- and low-tech industries. European Urban and Regional Studies, 18(3), 321-339.

Hansen, T., \& Winther, L. (2014). Competitive low-tech manufacturing and challenges for regional policy in the European context-lessons from the Danish experience. Cambridge Journal of Regions, Economy and Society, 7, p. 449-470, doi:10.1093/cjres/rsu015

Hardwick, P., \& Adams, M. (2002). Firm size and growth in the United Kingdom life insurance industry. The Journal of Risk and Insurance, 69(4), p. 577-593, doi:10.1111/1539-6975.00038.

Hatzichronoglou, T. (1996). Globalisation and Competitiveness: Relevant Indicators, OECD Science, Technology and Industry Working Papers, No. 1996/05, OECD Publishing, Paris. doi: http://dx.doi. org/10.1787/885511061376

Hatzichronoglou, T. (1997), "Revision of the High-Technology Sector and Product Classification",OECD Science, Technology and Industry Working Papers, No. 1997/02. doi: 10.1787/134337307632

Heinrich, T. (2013). Technological Change and Network Effects in Growth Regimes: Exploring the Microfoundations of Economic Growth. Routledge, Oxon and New York.

Heinrich, T. (2014). Standard wars, tied standards, and network externality induced path dependence in the ICT sector. Technological Forecasting and Social Change, 81, p. 309-320, doi: 10.1016/j.techfore.2013.04.015

Heinrich, T., \& Dai, S. (2016). Diversity of firm sizes, complexity, and industry structure in the Chinese economy. Structural Change and Economic Dynamics, 37, p. 90-106, doi: 10.1016/j.strueco.2016.01.001

Higson, C., Holly, S., \& Kattuman, P. (2002) The cross-sectional dynamics of the US business cycle: 1950-1999. Journal of Economic Dynamics and Control, 26, p. 1539-1555.

Higson, C., Holly, S., Kattuman, P., \& Platis, S. (2004) The business cycle, macroeconomic shocks and the cross-section: the growth of UK quoted companies. Economica, 71, p. 299-318.

Hirsch-Kreinsen, H., Jacobson, D., \& Robertson, P. L. (2006). 'Low-tech'Industries: Innovativeness and Development Perspectives-A Summary of a European Research Project. Prometheus, 24(1), 3-21., doi: 10.1080/08109020600563762

Hirsch-Kreinsen, H. (2008). 'Low-Tech' innovations. Industry and Innovation. 15(1), p. 19-43.

Hirsch-Kreinsen, H., \& Schwinge, I. (2011). Knowledgeintensive entrepreneurship and innovativeness in traditional industries: Conceptual framework and empirical findings, AEGIS project deliverable 1.3.1.

Hodorogel, R. G. (2009). The economic crisis and its effects on SMEs. Theoretical and Applied Economics, 5(534). p. 79-88. 
Holly, S., Petrella, I., \& Santoro, E. (2012). Aggregate fluctuations and the cross-sectional dynamics of firm growth. Journal of the Royal Statistical Society, 176 (2), p. 459-479, doi: 10.1111/j.1467-985X.2012.01047.x

Inklaar, R., \&Yang, J. (2012). The impact of financial crises and tolerance for uncertainty. Journal of Development Economics, 97(2), 466-480. doi:10.1016/j. jdeveco.2011.05.011.

lootty, M., Correa, P., Skrinjaric, B., \& Radas, S. (2014). Stylized facts on productivity growth: evidence from firm-level data in Croatia. Policy Research Working Paper, 6990, Trade and Competitiveness Global Practice Report (July 2014), World Bank Group.

Jaegers, T., Lipp-Lingua, C., \& Amil, D. (2013). High-technology and medium-high technology industries main drivers of EU-27's industrial growth. Available at: http://ec.europa. eu/eurostat/documents/3433488/5585612/KS-SF-13001-EN.PDF/f68ec994-79d3-43f2-a7a9-787b73fdfe7e. [Accessed 16 March 2017]

Kaloudis, A., Sandven, T., \& Smith, K. (2005). Structural change, growth and innovation: the roles of medium and low tech industries, 1980-2002, Perspectives on Economic, Political and Social Integration, Special Edition XI, p. 49-74.

Kangasharju, A. (2000). Regional variation in firm formation: Panel and cross-section data evidence from Finland. Papers in Regional Science, 79, p. 355-373.

Knudsen E. S., \& Lien L. B. (2014). Investments in Recessions. Advances in Strategic Management, 31, p. 3-36.

Liu, X. (2009). Impacts of the global financial crisis on small and medium enterprises in the People's Republic of China. ADBI Working Paper 180. Retrieved July 16, 2013, from: http://www.adbi.org/files/2009.12.16.wp180.impacts.gfc.enterprises.prc.pdf

Lotti, F., Santarelli, E., \& Vivarelli, M. (2009). Defending Gibrat's Law as a long-run regularity. Small Business Economics, 32(1), p. 31-44, doi:10.1007/s11187-007-9071-0.

Lunardi, J.T., Miccichè, S., Lillo, F., Mantegna, R. N., \& Gallegati, M. (2014). Do firms share the same functional form of their growth rate distribution? A statistical test. Journal of Economic Dynamics and Control, 39, p. 140-164.

Mansfield, E. (1962). Entry, Gibrat's Law, innovation and the growth of firms. American Economic Review, 52(5). p. 1023-1051.

MINPO. (2013). Strategy of entrepreneurship development in the Republic of Croatia 2013-2020. Zagreb: Ministry of Entrepreneurship and Crafts.

Moore, T., \& Mirzaei, A. (2016). The Impact of the Global Financial Crisis on Industry Growth. The Manchester School, 84, p. 159-180, doi: 10.1111/manc.12090

Nelson, R., \& Winter, S. (1982). An Evolutionary Theory of Economic Change. Cambridge, Ma.: The Belknap Press of Harvard University Press.
OECD (1994). Science and Technology Policy. Review and Outlook. Paris: OECD

OECD (2003). OECD Science, Technology and Industry Scoreboard 2003, OECD Publishing. doi: 10.1787/ sti_scoreboard-2003-en

Ogawa, K., \& Tanaka, T. (2013). The global financial crisis and small- and medium-sized enterprises in Japan: how did they cope with the crisis? Small Business Economics, 41, p. 401-417, doi: 10.1007/s11187-012-9434-z

Pavitt, K. (1984). Sectoral patterns of technical change: towards a taxonomy and a theory. Research Policy, 13, 343-373.

Perić, M., \& Vitezić, V. (2016). Impact of global economic crisis on firm growth. Small Business Economics, 46 (1). p. 1-12, doi: 10.1007/s11187-015-9671-z

Pisano, G. P., \& Shih, W. C. (2009). Restoring American competitiveness. Harvard Business Review, 87, p. 114-125.

Pop, L. N., Rovinaru, F., \& Rovinaru, M. (2013). Commodity price volatility during and after the economic crisisImplications for Romania. South East European Journal of Economics and Business, 8(1), 45-52. doi: 10.2478/ jeb-2013-0003

Protogerou A., Caloghirou, Y., \& Karagouni, G. (2013). The relevance of the dynamic capabilities perspective in lowtech sectors, in Knowledge-Intensive Entrepreneurship in Low-Tech Sectors: The Prospects of Traditional Economic Industries, H. Hirsch-Kreinsen and I. Schwinge (eds.), Edward Elgar Publishing, UK.

Rafferty, A., Rees, J., Sensier, M., \& Harding, A. (2013). Growth and recession: Underemployment and the labour market in the North of England. Applied Spatial Analysis and Policy, 6(2), 143-163. doi:10.1007/s12061-013-9089-4.

Rammer, C., \& Schubert, T. (2016). Concentration on the few? R\&D and innovation in German firms between 2001 and 2013, Fraunhofer ISI Discussion Papers Innovation Systems and Policy Analysis, No. 54.

Reichstein, T., \& Jensen, M. B. (2005). Firm size and firm growth rate distributions-the case of Denmark. Industrial and Corporate Change, 14(6), 1145-1166.

Schumpeter, J. A. (1934). Theory of Economic Development. Harvard University Press, Cambridge, MA.

Schumpeter, J. (1939). Business Cycles: A Theoretical, Historical, and Statistical Analysis of the Capitalist Process. London: McGraw-Hill.

Siemer, M. (2014) Firm entry and employment dynamics in the great recession. Finance and Economics Discussion Series, Divisions of Research \& Statistics and Monetary Affairs. Washington D.C.: Federal Reserve Board.

Stanley, M. H., Amaral, L. A., Buldyrev, S. V., \& Havlin, S. (1996). Scaling behaviour in the growth of companies. Nature, 379(6568), 804-805.

Stark, P. B. (2008). Density Estimation. Berkley. Available at: https://www.stat.berkeley.edu/ stark/Teach/S240/ Notes/ch1.pdf [Accessed 12 April 2017] 
Stojčić, N., \& Aralica, Z. (2018). (De) industrialisation and lessons for industrial policy in Central and Eastern Europe. Post-Communist Economies, p. 1-22. doi: 10.1080/14631377.2018.1443251

Sutton, J. (1997). Gibrat's Legacy. Journal of Economic Literature, 35 (1), p. 40-59.

Szirmai, A. (2012). Industrialisation as an engine of growth in developing countries 1950-2005. Structural Change and Economic Dynamics, 23, p. 406-420. doi: 10.1016/j. strueco.2015.06.002.

Szirmai, A., \& Verspagen, B. (2015). Manufacturing and economic growth in developingcountries, 1950-2005. Structural Change and Economic Dynamics, 34, p. 46-59. doi: 10.1016/j.strueco.2015.06.002.

Tipurić, D. \& Pejić Bach, M. (2009). Changes in Industrial Concentration in the Croatian Economy (1995-2006). Working Paper Series, Paper No. 09-03, Faculty of Economics and Business, University of Zagreb
Tirole, J. (1988). The Theory of Industrial Organization. MIT Press.

Von Tunzelmann, N., \& Acha, V. (2005). Innovation in "lowtech" industries. In The Oxford handbook of innovation.

Watson, J. (2012). Networking: gender differences and the association with firm performance. International Small Business Journal, 30(5). p. 536-558.

Williams,M. A., Pinto, B. P., \& Park, D. (2015). Global evidence on the distribution of firm growth rates. Physica $A$ : Statistical Mechanics and its Applications, 432, 15, p.102107, doi: 10.1016/j.physa.2015.02.103.

Xu, L., Bedrick, E. J., Hanson, T., \& Restrepo, C. (2014). A Comparison of Statistical Tools for Identifying Modality in Body Mass Distributions. Journal of Data Science, 12, p.175-196.

Zenghelis, D. (2012). A Strategy for Restoring Confidence and Economic Growth through Green Investment and Innovation. Policy brief. London: Grantham Institute, London School of Economics.

Appendix 1: Firm size distribution - overall manufacturing, low-tech and high-tech sectors

Manufacturing aggregate

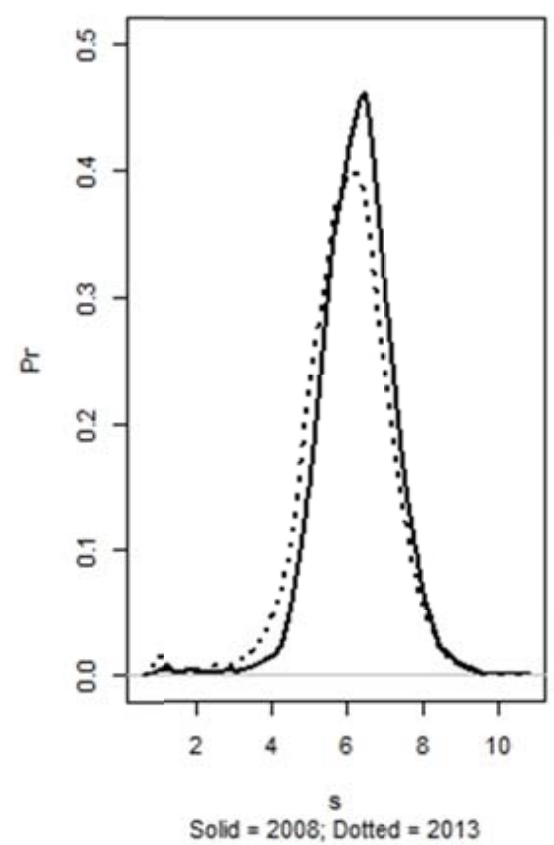

Low-tech sectors

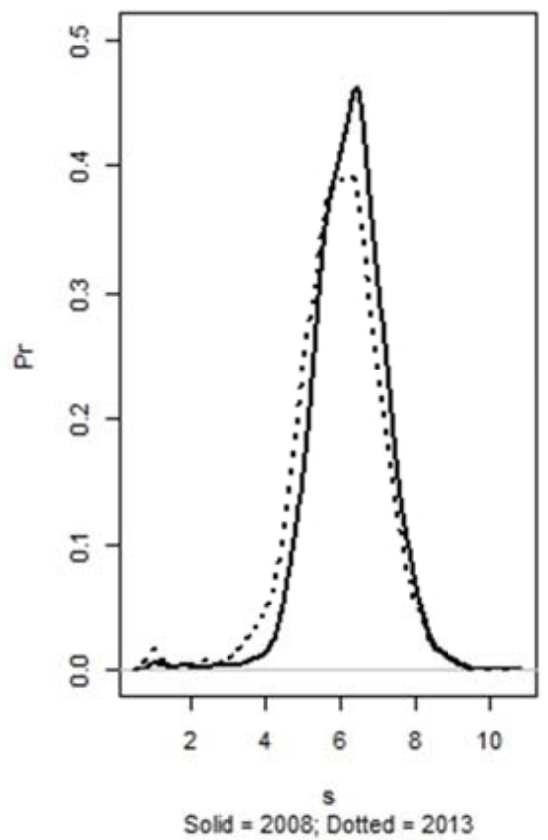

High-tech sectors

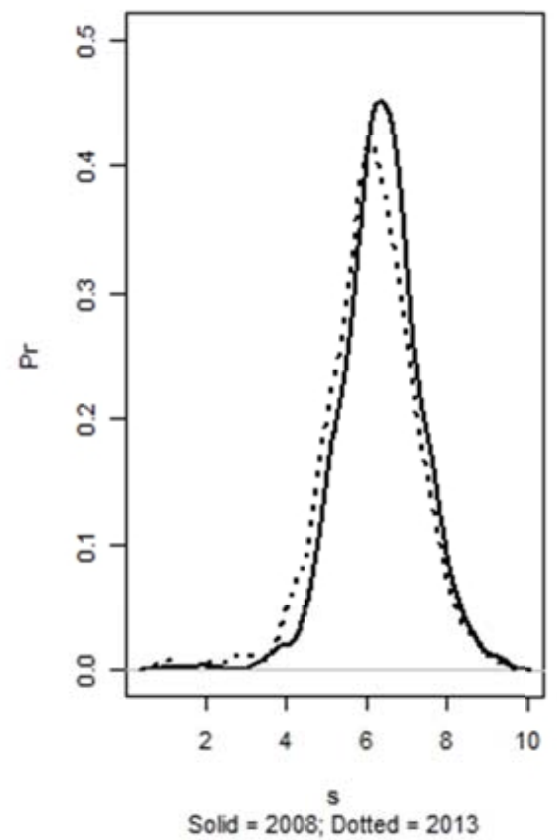



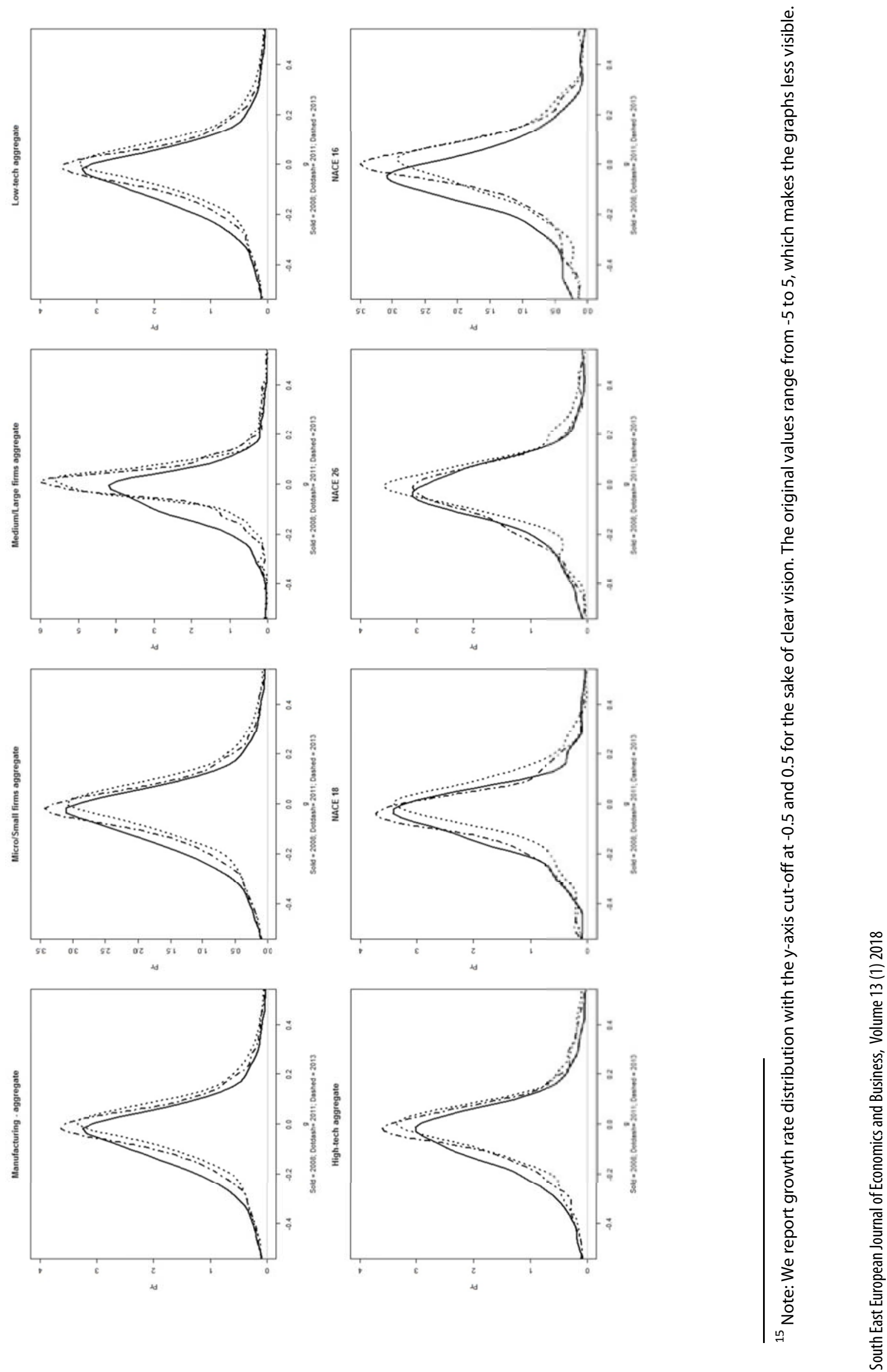


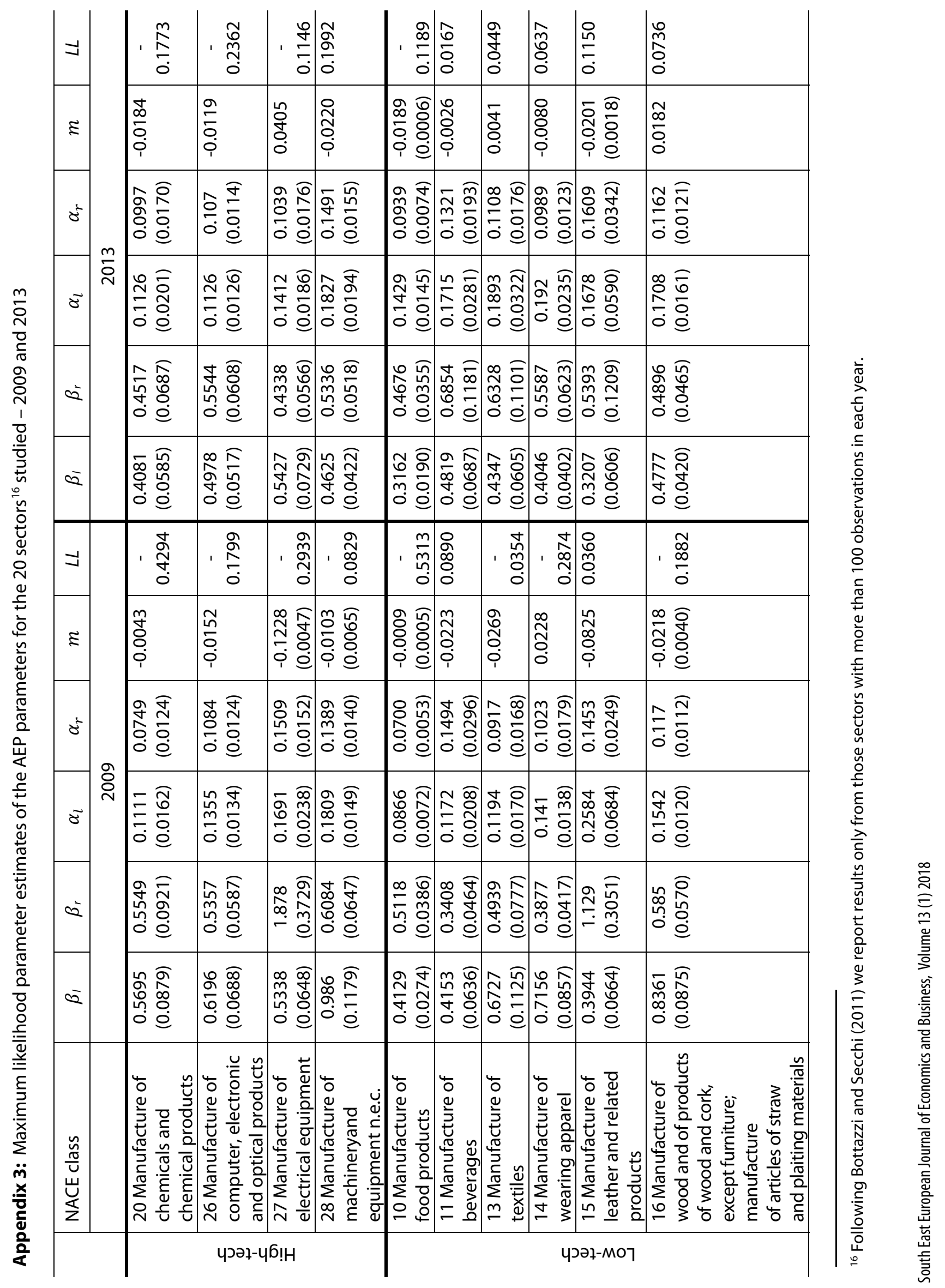




\begin{tabular}{|c|c|c|c|c|c|c|c|c|c|}
\hline 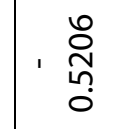 & , $\begin{array}{l}0 \\
0 \\
0 \\
0\end{array}$ & $\underset{\frac{\sigma}{\sigma}}{\frac{\sigma}{0}}$ & $\underset{+}{\stackrel{+}{\Xi}}$ & 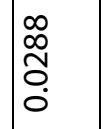 & 岕 & 紊 & 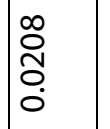 & & $\mid \begin{array}{l}n \\
0 \\
0 \\
0\end{array}$ \\
\hline $\begin{array}{l} \\
\\
0 \\
0 \\
0\end{array}$ & 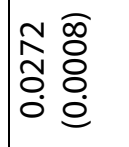 & $\begin{array}{l}\infty \\
0 \\
0 \\
0 \\
0 \\
0\end{array}$ & 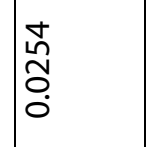 & 픙 & 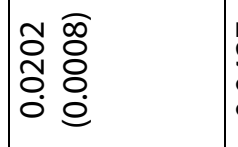 & 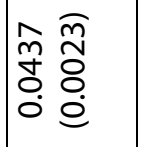 & 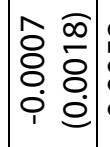 & & 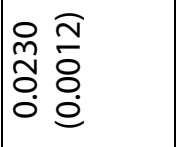 \\
\hline 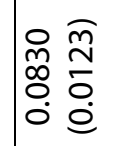 & 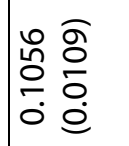 & $\begin{array}{ll}m & \overline{0} \\
\hat{\alpha} & 0 \\
0 & 0 \\
0 & 0 \\
0\end{array}$ & 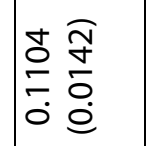 & 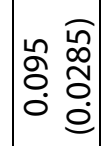 & 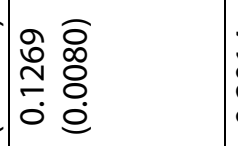 & 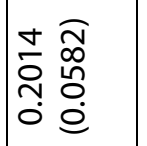 & 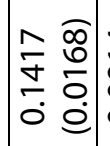 & 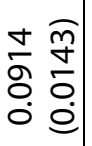 & 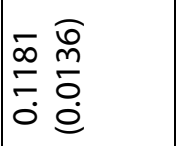 \\
\hline $\begin{array}{l}\hat{\infty} \\
\stackrel{\bar{D}}{\mathcal{O}} \\
\stackrel{0}{0} \\
\dot{0}\end{array}$ & 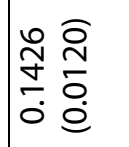 & 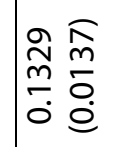 & 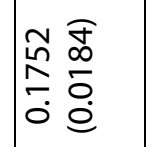 & 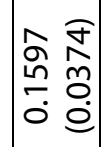 & 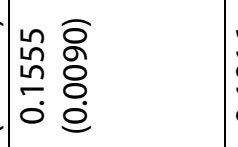 & 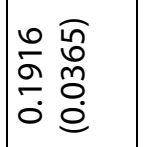 & $\begin{array}{ll}\infty & \widehat{0} \\
0 & 0 \\
\delta & 0 \\
0 & 0 \\
0\end{array}$ & 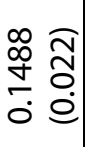 & 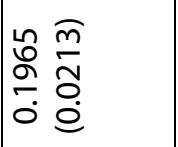 \\
\hline 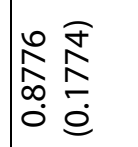 & 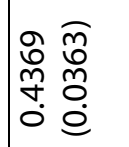 & $\begin{array}{l}\frac{m}{\tilde{m}} \\
\frac{\tilde{m}}{0} \\
0 \\
0\end{array}$ & 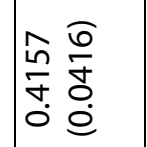 & 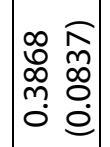 & 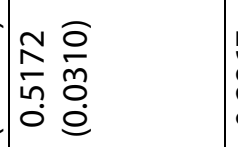 & 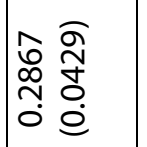 & 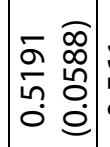 & $\begin{array}{ll} & \widehat{c} \\
\overline{0} & 0 \\
0 & 0 \\
0 & 0 \\
0 & 0 \\
0\end{array}$ & 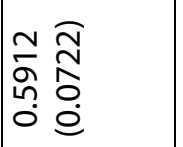 \\
\hline 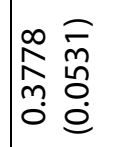 & 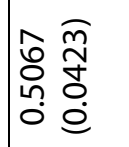 & \begin{tabular}{ll}
2 & 0 \\
$\partial$ & 0 \\
\multirow{y}{*}{} & 0 \\
0 & 0
\end{tabular} & 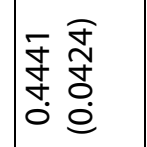 & 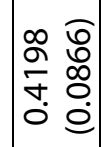 & 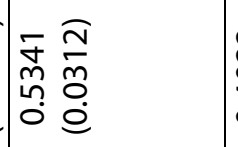 & 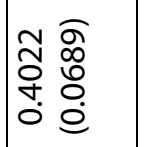 & 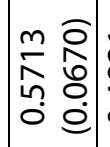 & $\begin{array}{l}\sqrt{\hat{0}} \\
0 \\
0 \\
0\end{array}$ & 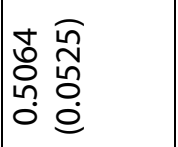 \\
\hline 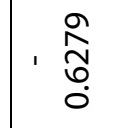 & 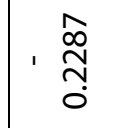 & , & , & 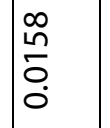 & 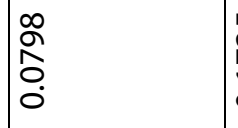 & 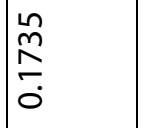 & , $\begin{array}{l}0 \\
\\
0 \\
0\end{array}$ & $\begin{array}{r}0 \\
1 \\
1 \\
o \\
0\end{array}$ & , \\
\hline : & $\begin{array}{l}\tilde{N} \\
\widetilde{N} \\
0 \\
\grave{i}\end{array}$ & 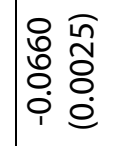 & 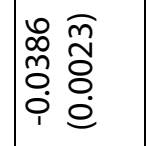 & 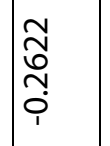 & $\frac{\infty}{\infty}$ & $\mid \begin{array}{l}\hat{a} \\
\vdots \\
0 \\
0 \\
i\end{array}$ & 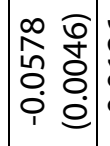 & \begin{tabular}{ll} 
& \\
& $\bar{m}$ \\
0 & 0 \\
\hdashline & 0 \\
& 0
\end{tabular} & 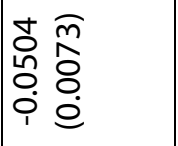 \\
\hline 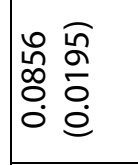 & 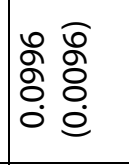 & 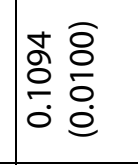 & 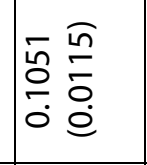 & 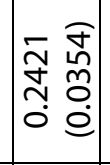 & 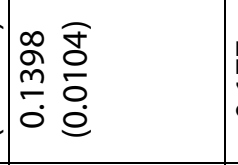 & $\begin{array}{ll}\widehat{N} & \widehat{N} \\
\hat{N} & 0 \\
0 & 0 \\
0 & 0\end{array}$ & 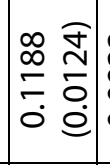 & 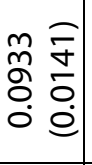 & 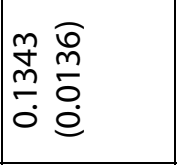 \\
\hline 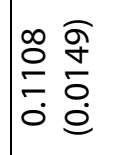 & 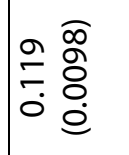 & $\frac{m}{\frac{0}{0}} \frac{0}{0}$ & 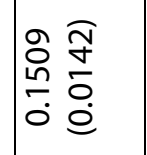 & 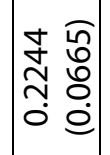 & 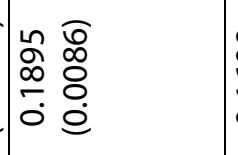 & 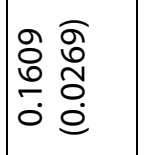 & 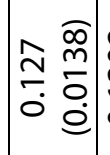 & 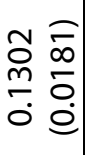 & 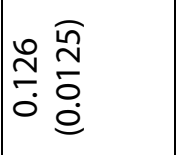 \\
\hline 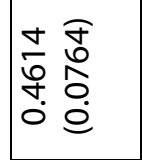 & 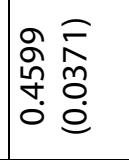 & 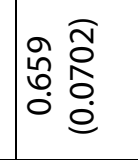 & 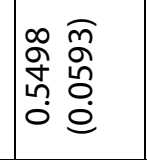 & 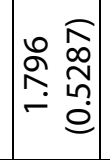 & $\begin{array}{ll}0 & \widehat{0} \\
0 & 0 \\
0 & 0 \\
0 & 0 \\
0\end{array}$ & 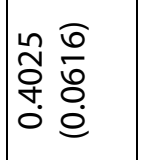 & 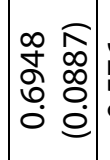 & $\begin{array}{lll}0 & \widehat{\alpha} \\
0 & 0 \\
& 0 \\
0 & 0 \\
0 & 0\end{array}$ & 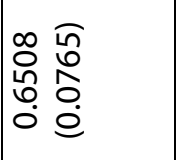 \\
\hline 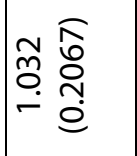 & 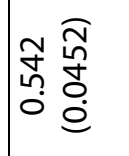 & 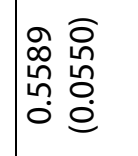 & 항 & 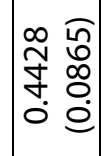 & 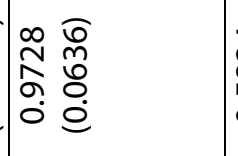 & 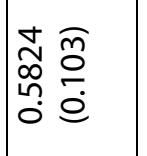 & 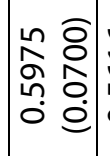 & 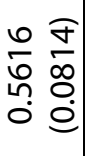 & 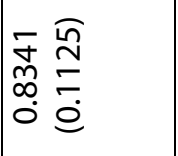 \\
\hline 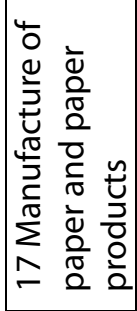 & 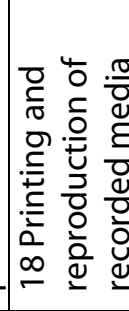 & 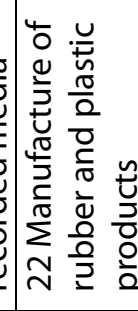 & 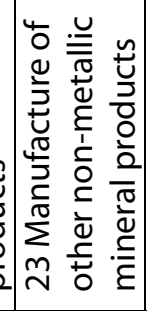 & 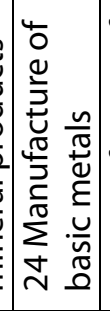 & 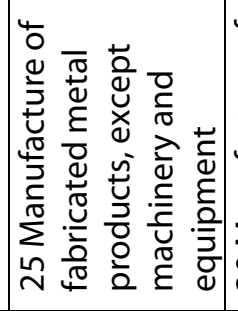 & 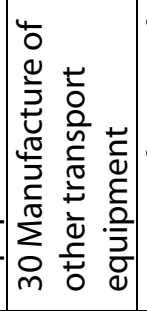 & 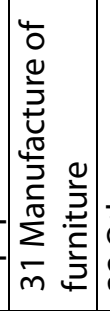 & 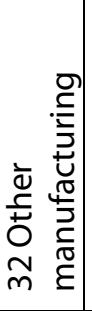 & 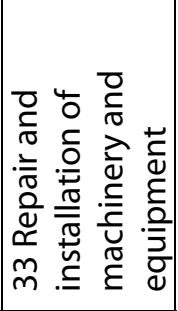 \\
\hline
\end{tabular}




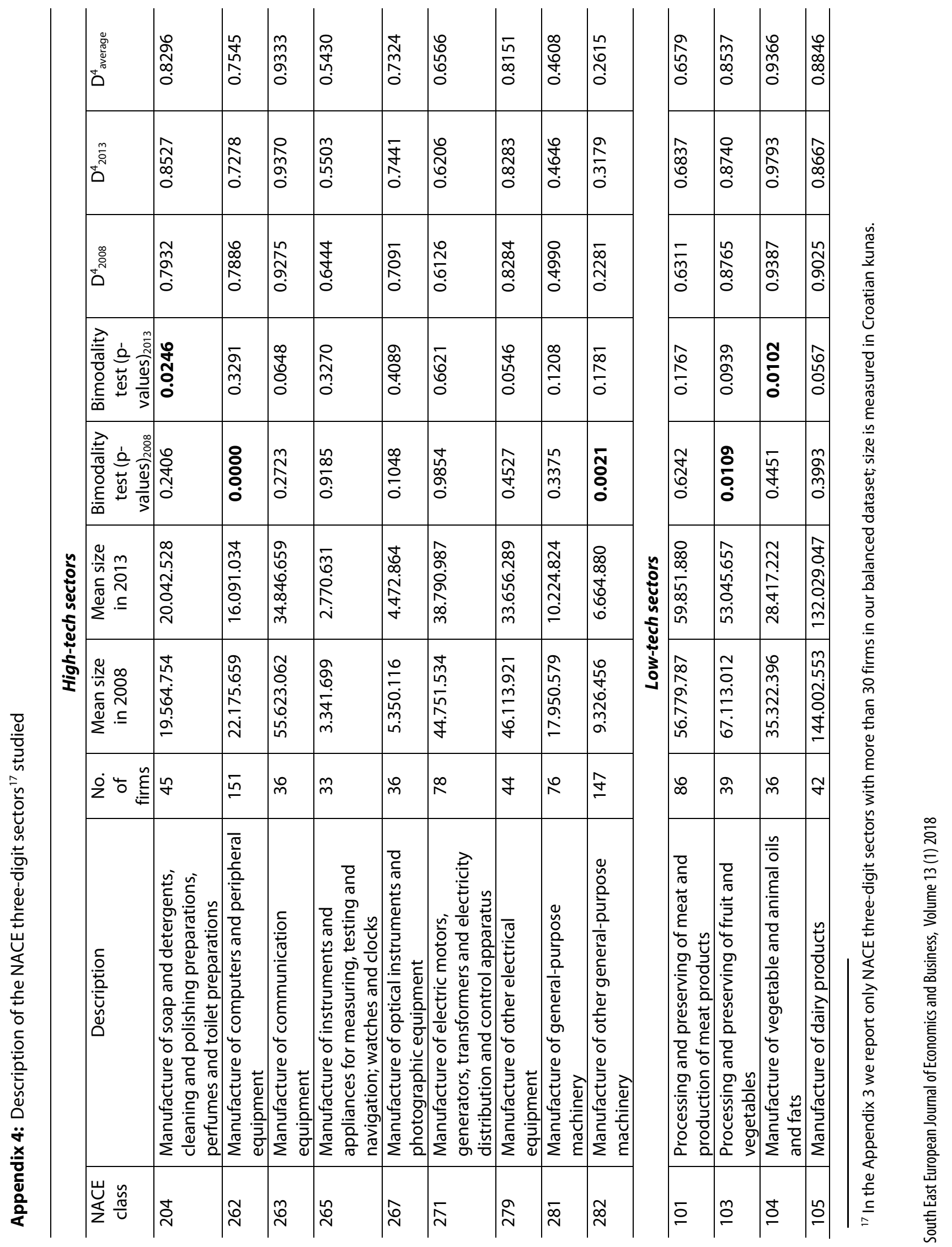




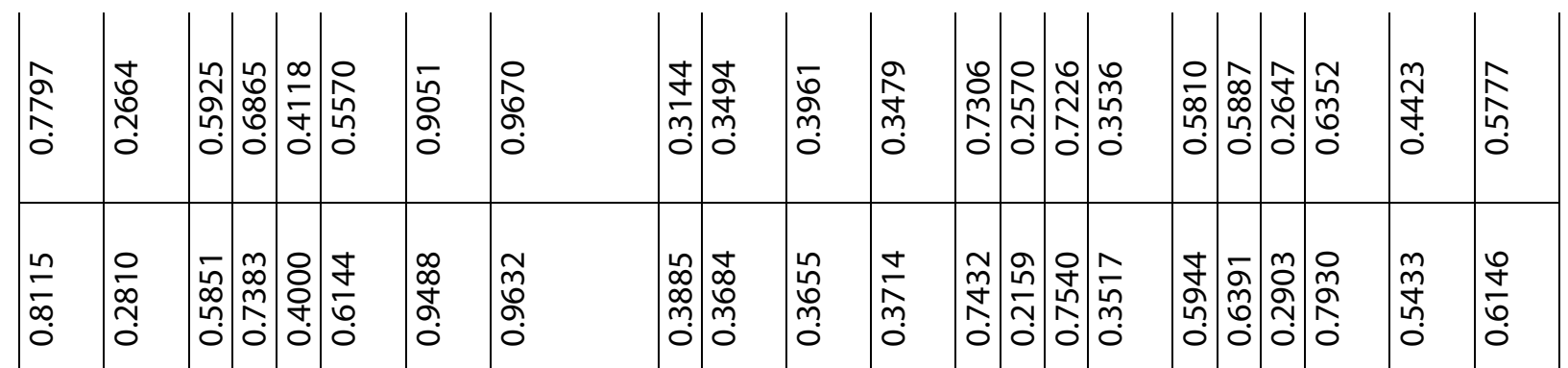

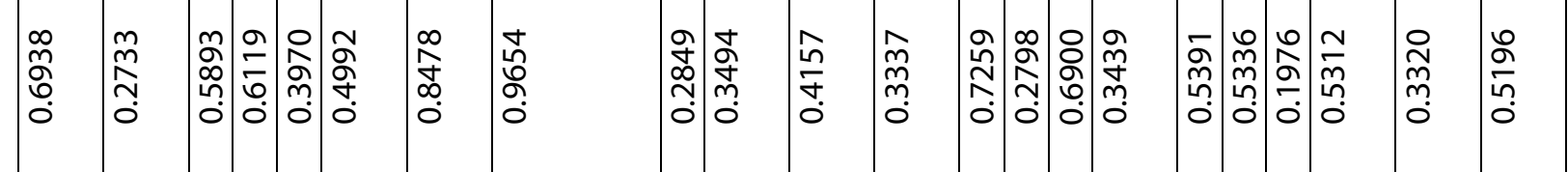

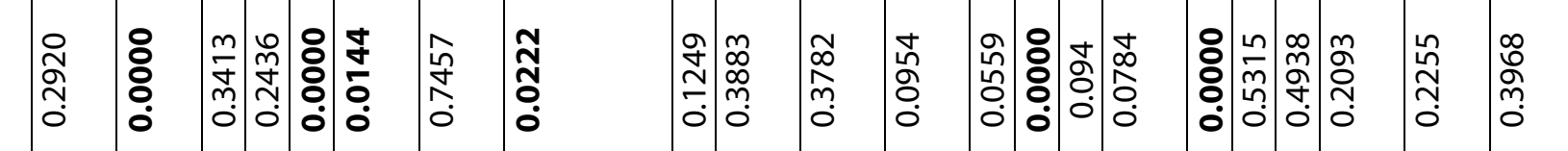

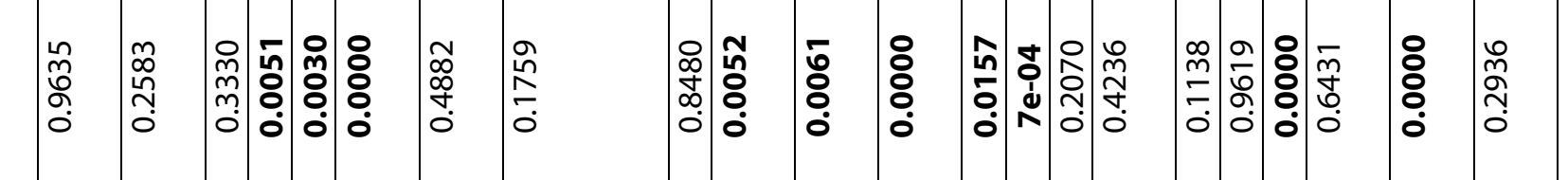

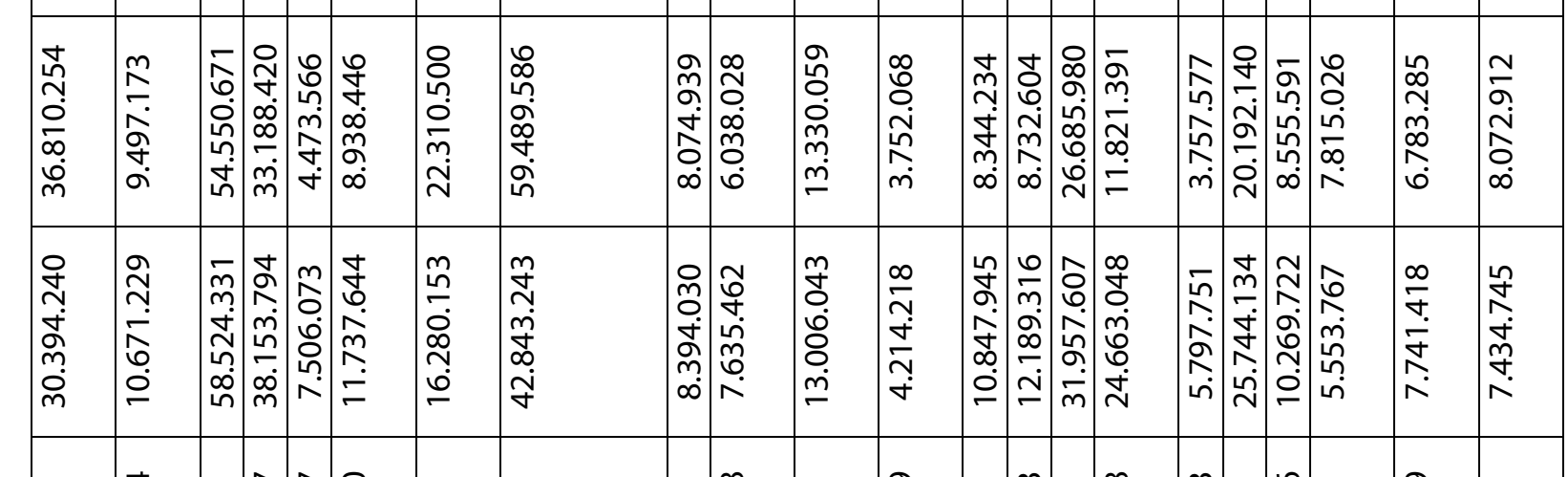

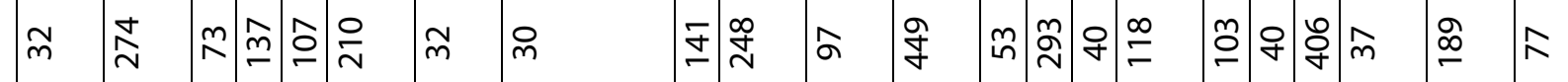

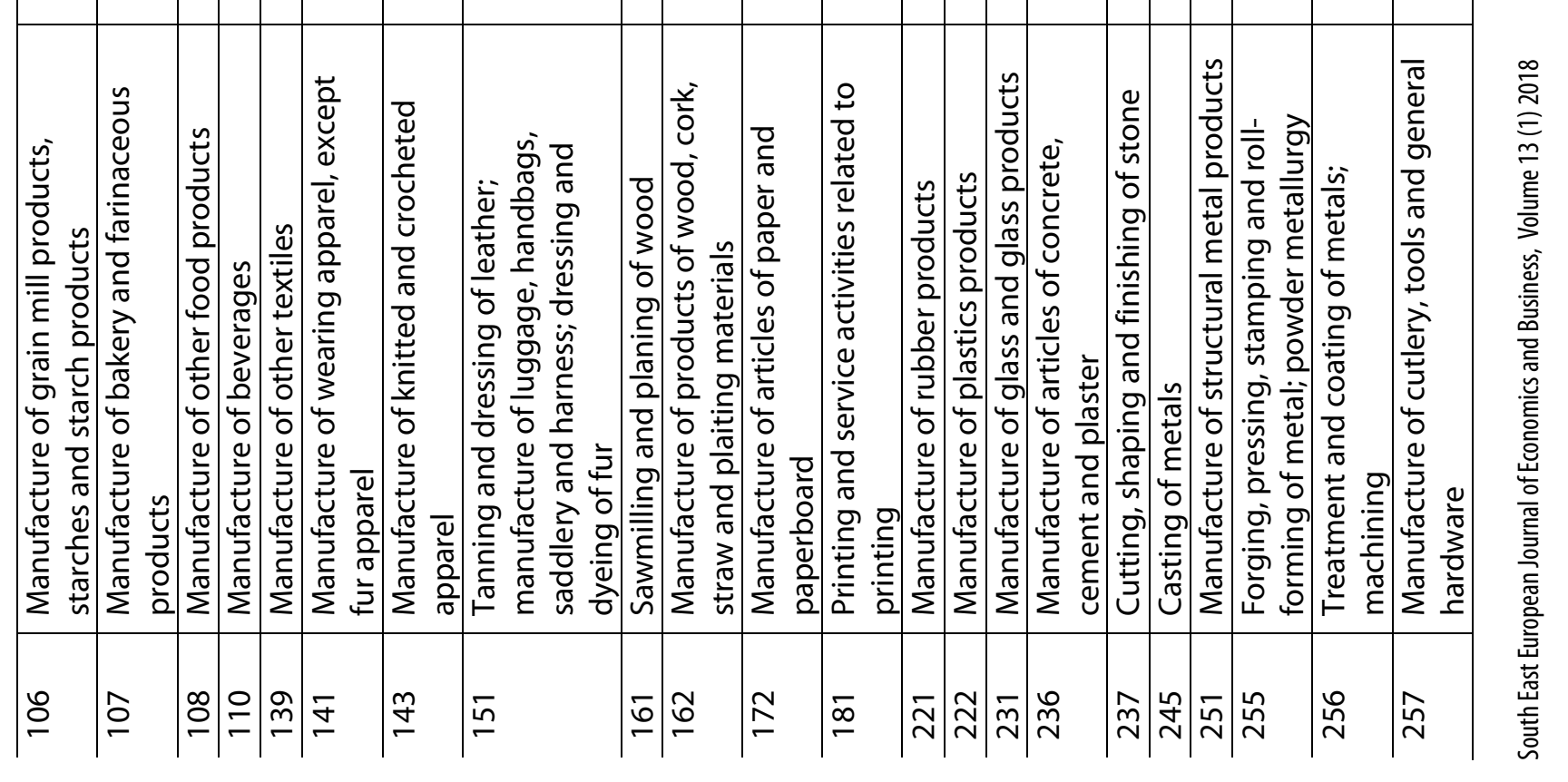




\begin{tabular}{|c|c|c|c|c|c|c|}
\hline 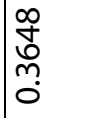 & مُ & $\left|\begin{array}{c}\tilde{D} \\
m \\
m \\
0 \\
0\end{array}\right|$ & $\frac{\hat{\sigma}}{\frac{\sigma}{\alpha}}$ & $\begin{array}{l}m \\
\tilde{n} \\
n \\
0 \\
0\end{array}$ & $\begin{array}{l}\hat{m} \\
\hat{n} \\
0 \\
0\end{array}$ & $\begin{array}{l}\text { N } \\
\infty \\
i n \\
0 \\
0\end{array}$ \\
\hline 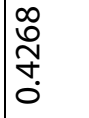 & 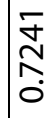 & $\mid \begin{array}{c}\tilde{0} \\
m \\
m \\
0\end{array}$ & 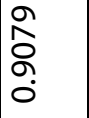 & \begin{tabular}{l} 
సે \\
\multirow{+}{*}{} \\
0
\end{tabular} & 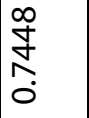 & 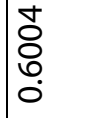 \\
\hline $\begin{array}{l}m \\
\infty \\
0 \\
m \\
0 \\
0\end{array}$ & $\begin{array}{l}\infty \\
\stackrel{\infty}{\kappa} \\
0\end{array}$ & $\mid \begin{array}{c}\mathcal{N} \\
m \\
\tilde{o} \\
\tilde{s}\end{array}$ & 离 & $\begin{array}{l}m \\
\tilde{m} \\
\text { గn } \\
0\end{array}$ & $\begin{array}{l}\infty \\
\infty \\
o \\
0 \\
0 \\
0\end{array}$ & $\begin{array}{l}n \\
6 \\
0 \\
0 \\
0 \\
0\end{array}$ \\
\hline : & 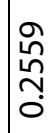 & $\left|\begin{array}{l}n \\
0 \\
0 \\
0 \\
0\end{array}\right|$ & 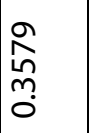 & $\begin{array}{c}\frac{m}{5} \\
\frac{0}{0}\end{array}$ & $\frac{m}{o}$ & $\begin{array}{l}\text { ภू } \\
\text { ָุ }\end{array}$ \\
\hline 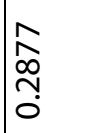 & $\begin{array}{l}0 \\
\stackrel{0}{n} \\
\\
0\end{array}$ & $\mid \begin{array}{l}0 \\
\grave{0} \\
0 \\
0\end{array}$ & 会 & $\begin{array}{l}m \\
\hat{\alpha} \\
0 \\
0 \\
0\end{array}$ & $\begin{array}{l}\frac{m}{0} \\
\frac{0}{0} \\
\end{array}$ & : \\
\hline 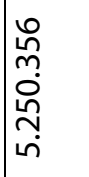 & 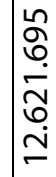 & $\mid \begin{array}{c}0 \\
0 \\
\infty \\
0 \\
0 \\
\infty \\
\infty\end{array}$ & 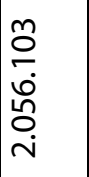 & 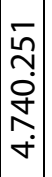 & $\begin{array}{l}0 \\
1 n \\
1 n \\
0 \\
b \\
\infty \\
0 \\
\sigma\end{array}$ & 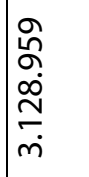 \\
\hline $\mid \begin{array}{l}\infty \\
\stackrel{\infty}{N} \\
\infty \\
o \\
\hat{o} \\
0 \\
0\end{array}$ & 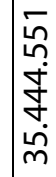 & $\mid \begin{array}{c}\mathfrak{y} \\
\dot{J} \\
\mathfrak{d} \\
\mathfrak{N} \\
\overline{=}\end{array}$ & $\begin{array}{l}\bar{\sigma} \\
\hat{\sigma} \\
\frac{\sigma}{\infty} \\
\infty \\
\dot{-}\end{array}$ & $\begin{array}{c}\bar{m} \\
\\
\dot{\omega} \\
\infty \\
\dot{0}\end{array}$ & $\begin{array}{l}\stackrel{N}{N} \\
\infty \\
\infty \\
\infty \\
\end{array}$ & 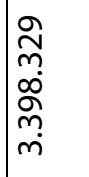 \\
\hline$\stackrel{\sim}{N}$ & $\stackrel{\infty}{\circ}$ & $\stackrel{\hat{\omega}}{\sim}$ & $\bar{m}$ & 守 & $\stackrel{\text { no }}{\circ}$ & $\infty$ \\
\hline 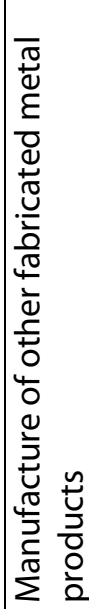 & 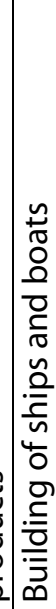 & 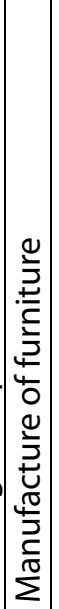 & 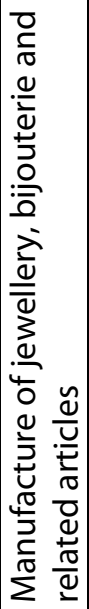 & 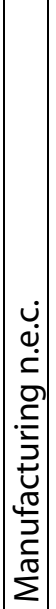 & 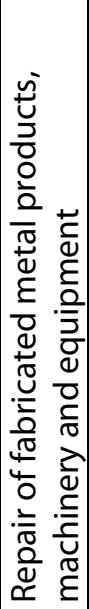 & 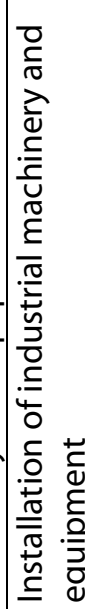 \\
\hline 望 & & & $\bar{\pi}$ & & & $\underset{m}{\tilde{m}}$ \\
\hline
\end{tabular}

